\title{
Appropriating Information Technology Artefacts through Trial and Error: The Case of the Tablet
}

\author{
Efpraxia D. Zamani ${ }^{1}$ (D) - Nancy Pouloudi ${ }^{2} \cdot$ George M. Giaglis $^{3,4} \cdot$ Jonathan Wareham $^{5}$
}

Accepted: 10 September 2020 / Published online: 18 September 2020

(C) Springer Science+Business Media, LLC, part of Springer Nature 2020

\begin{abstract}
The concept of appropriation is of paramount importance for the lasting use of an Information Technology (IT) artefact following its initial adoption, and therefore its success. However, quite often, users' original expectations are negatively disconfirmed, and instead of appropriating the IT artefact, they discontinue its use. In this study we examine the use of IT artefacts following negative disconfirmation and use Grounded Theory Method techniques to analyse 136 blogposts, collected between March 2011 - July 2017, to investigate how users appropriate or reject the tablet when technology falls short of users' expectations. Our findings show that users overcome negative disconfirmation through a trial and error process. In doing so, we identify that users appropriate the tablet when the attained benefits significantly outweigh the risks or sacrifices stemming out of its use. We discuss our contribution within the context of the appropriation literature, and highlight that the success of IT lies with the user's success in identifying personal use scenarios within and across diverse contexts of use.
\end{abstract}

Keywords Trial and error - Grounded theory method - User behaviour · Appropriation $\cdot$ Rejection $\cdot$ Tablet $\cdot$ Negative disconfirmation

\section{Introduction}

Contemporary Information Technology (IT) devices are boundary spanning and accommodate different contexts of use, covering both professional and personal use scenarios. Such IT devices can be smartphones and tablets, among others, and their adoption and use is largely volitional (Schmitz et al. 2016), which means that the individual user is able to decide and control their use. This indicates a great heterogeneity of potential uses, and further signifies increased user control over a device's adoption, modification, and even rejection. These two points create an important challenge

Efpraxia D. Zamani

e.zamani@sheffield.ac.uk

Nancy Pouloudi

pouloudi@aueb.gr

George M. Giaglis

giaglis@aueb.gr

Jonathan Wareham

jonathan.wareham@esade.edu

1 Information School, The University of Sheffield, Regent Court, 211 Portobello, Sheffield S1 4DP, UK where the user can easily switch between contexts, with IT having to satisfy their requirements irrespective of the changing environments. This is important because the success of an IT artefact resides with the user identifying a benefit in IT use against the background of personal use scenarios.

For this reason, today there is a large body of research that examines why users accept an IT artefact and how they make use of it (Barnett et al. 2015). Often, these studies draw from theories, such as the Technology Acceptance Model (Davis and Warshaw 1989), the Unified Theory of Acceptance and Use of Technology (Venkatesh et al. 2003) and their variations (Kim and Garrison 2009; e.g., Venkatesh et al. 2011;

2 Department of Management Science and Technology, Athens University of Economics and Business, 47A Evelpidon \& 33 Lefkados Str, 1362 Athens, Greece

Institute for the Future (IFF), University of Nicosia, 46 Makedonitissas Avenue, CY-2417 Nicosia, Cyprus

4 Department of Management Science and Technology, Athens University of Economics and Business, 47A Evelpidon \& 33 Lefkados Str, 1362 Athens, Greece

5 Department of Operations, Innovation and Data Sciences, ESADE, Avenida de Torreblanca, 59, 08172 Sant Cugat, Spain 
Venkatesh and Davis 2000). These theories place the emphasis on the factors that drive user decision with regard to the acceptance or rejection of the technology (Aggarwal et al. 2015). However, because these theories place the emphasis on the preliminary stages of user interaction, less or no emphasis is inescapably given in how users actually make use of the technology, which exerts a greater impact on its viability (Venkatesh et al. 2011).

The aspect of how users make use of IT is typically examined by post-adoption user behaviour studies (Zamani et al. 2019), and often through the lens of appropriation which explains how users adapt and modify the IT or even refine their IT use in order to achieve their goals (Clark 1987). Studies often focus on the fit among user, task and IT (e.g., Barki et al. 2007) or the variations of appropriation acts and adaptations (e.g., Pallud and Elie-dit-Cosaque 2011). However, existing research has two main shortcomings. First, there is a key assumption that a fit can be achieved via appropriation. Second, research mainly focuses on organisational systems within enterprise-focused contexts (e.g., A. Bhattacherjee and Premkumar 2004; Jasperson et al. 2005). Even when the unit of analysis is set at the individual level, the user is approached as an organizational member (e.g., Ahuja and Thatcher 2005). As a result, appropriation studies often miss the particularities of IT where appropriation is not necessarily side-stepping top-down imposed use patterns but equally an effort to satisfy user goals.

In this paper, we are interested in seeing "what is the process of appropriation of IT devices by individual and volitional users following negative disconfirmation?" This is of distinct importance. Disconfirmation denotes the discrepancy between the user's original expectations and their perceptions regarding the actual performance of the IT device post-usage (A. Bhattacherjee and Premkumar 2004). Positive disconfirmation suggests that the user is pleasantly surprised but negative disconfirmation is crucial as it often leads to discontinuance behaviour and the abandonment of the IT device. It is thus imperative to understand how, rather than abandoning the IT device, the user can be successful and incorporate it successfully, within their portfolio of other IT devices. Appropriation signifies the situation where the user has managed to overcome the said discrepancies, and made the IT device their own, using adaptations and modifications (A. K. Barrett 2018; Clark 1987). Most importantly, appropriation leads to habitual norms and routines (Dennis et al. 2001), and as such, to the lasting use of the IT device (Wu et al. 2017), which is what makes an IT device fairly successful.

We use the tablet as an exemplary case, and specifically the iPad. We chose to focus on the iPad because since its launch, it has been consistently popular among the mass consumer market, and because it has attracted the attention of both practitioners and end users (Zamani et al. 2019). We use Grounded Theory Method (GTM) techniques specifically because our aim is to develop a theory grounded on the data, using systematic ways for data collection and analysis, while taking stock of prior research and with the objective to enrich the appropriation literature. Our empirical material consists of blog posts, covering 7 years. We analysed this material following the approach put forward by Volkoff et al. (2007) by drawing iteratively from the relevant literature and our data, and examining the empirical material through the lenses of competing theories. This resulted in the identification of behavioural patterns that are compatible with the concept of trial and error.

Our contributions are twofold. First, we introduce trial and error as a new variation of appropriation that addresses some of the observed shortcomings of the existing variations. Second, we study user behaviour with contemporary, highly popular IT devices. As their use is not necessarily organizationally mandated, their success relies on the users identifying personal use scenario(s) that can serve them within and across diverse contexts of use. Against this background, understanding the processes users go through while moving from negative disconfirmation to appropriation is of crucial importance for the success of the examined IT devices within these diverse contexts.

In what follows, we first discuss prior work on appropriation. We then present the methods used and our findings. Then, we discuss our findings in relation to the existing literature and theorise on trial and error. We conclude our paper with the contributions of our research and its limitations.

\section{Background Literature}

Appropriation is a prerequisite for the sustained and lasting use of IT systems as it feeds into the formulation of norms and routines (Dennis et al. 2001) by supporting users In developing personal use scenarios (Mäkelä and Vellonen 2018; Wu et al. 2017). As such, appropriation is core for the success of IT artefacts. In the next section we examine the different variations of appropriation.

\subsection{Appropriation of IT}

Clark (1987) defines appropriation as the "situation where the user starts by recognizing the potential value of a particular IT and manages to narrow the absorption gap between the requirements of the IT and its own limited capacities" (p. 156). Similarly, Carroll and Fidock (2011) describe the concept as "seeking a relationship with the technology so that it provides benefit to the user through supporting practices, enabling new - and beneficial - practices or removing ineffective practices" (p. 4). Existing research emphasizes the impact of appropriation on performance (e.g., Beaudry and Pinsonneault 1998; DeSanctis and Poole 1994) with several 
studies analysing its different variations, ranging from workarounds (e.g., Alter 2014) and adaptations (e.g., ElieDit-Cosaque and Pallud 2010) to improvisations (e.g., McGann and Lyytinen 2008). By far, the most well research variations are those of adaptations and workarounds.

According to Beaudry and Pinsonneault (1998), adaptation guarantees a fit between technology and user, as a result of the user changing routines and habits, enriching their skillset, and changing the technology with the aim to achieve their goals. Schmitz et al. (2016) have further extended this concept through the lens of Adaptive Structuration Theory and discuss that, as a result of the technology's malleability, users adapt the technology and their tasks either subtly and progressively (exploitive adaptation) or more exploratively, by reinterpreting the technology and its features (explorative adaptation). The explorative type of adaptation is quite similar to the enhanced use of IT, proposed by Bagayogo et al. (2014), where the user attempts to find new ways of using features of an IT system. This may include using previously unused or underutilised features (Bagayogo et al. 2014). The exploitive type of adaptation strongly resembles the deep structure usage, proposed by DeSanctis \& Poole (DeSanctis and Poole 1994), whereby both approaches focus on the extent and the intensity of the use of IT features for task completion, and the user efforts to progressively use more and more IT features and functions.

While in all the aforementioned approaches there is a common element of learning (Kwahk et al. 2018) where users recognise and put in use new approaches to task completion (Barki et al. 2007), there are differences as well. Namely, enhanced use of IT emphasizes that IT use may change over time (Bagayogo et al. 2014), whereas Schmitz et al. (2016) and Beaudry and Pinsonneault (1998) focus more on the identification of a fit among task and technology or technology and user. On the other hand, deep structure usage is a rather more demanding form of usage (Tams et al. 2018), as it entails that users comprehend how the system is structured (BurtonJones and Straub 2006).

In the effort of identifying a fit and appropriating an IT device, IT is not used as originally designed (Schmitz et al. 2016). User modifications may or may not be in the spirit of the original design (DeSanctis and Poole 1994), and essentially become workarounds (Alter 2014) as the user engages with IT outside recommended rules (Ferneley and Sobreperez 2006). Workarounds are often seen as a form of resistance behaviour within an organizational setting. Yet, numerous studies to date show that, when workarounds become stable over time, they are merely an indication of an inadequately designed information system (Ferneley and Sobreperez 2006), and should be seen as integral for the completion of day-today work (e.g., Azad and King 2011). As workarounds are often developed for tackling in situ newly emergent shortcomings, they are closely related to revisions of IT use (Sun 2012) and improvisation acts (Morrison 2015).
Revisions of IT use concern primarily the way users revise their IT use due to novel and challenging situations when users are faced with discrepancies or other deliberate initiatives (Sun 2012). Such revisions allow users to meet their needs and overcome inadequacies of IT and processes (Lee et al. 2018). Within this context, users may try new features, substitute older ones, or combine some and even repurpose them, in their attempt to make better use of existing and new IT features, functions and extensions (Sun 2012). In this sense, revisions of IT as an appropriation variation shares a common focus with enhanced IT use on how IT use may change over time, as it emphasizes that "a person's [technological features in use] is always in flux" (Sun 2012, p. 455).

Such novel uses of IT in light of shortcomings, resource shortages and other workplace challenges can equally take the form of improvisation acts (Morrison 2015). Combining, recombing and repurposing IT denotes an attempt to try out different things in order to solve problems. In doing so, users may cast a wide net that goes well beyond what they know, which allows them to innovate and identify novel solutions (Scheiner et al. 2016). While trying to find new ways of using IT, users essentially try to innovate (Tams et al. 2018), and in doing so they make IT their own (Ahuja and Thatcher 2005). Workplace innovation with IT suggests that, users seek to incorporate IT in their processes (Wu et al. 2017) while attempting to do away with the restrictions enacted by IT itself (Schmitz et al. 2016). The difference between trying to innovate with IT and improvisation is that first places emphasis on one's goals about the outcome of the interaction (Ahuja and Thatcher 2005), while the second entails thinking and acting "simultaneously and on the spur of the moment" (Ciborra 1999, p. 78). Therefore, while trying to innovate can be seen as one's behavioural coping toward identifying new uses for existing systems and ways to support new tasks (Wu et al. 2017), improvisation is often seen as unpredictable because users need to work with whatever is available (Ciborra 2002) as a result of e.g., resource shortages (Morrison 2015).

Table 1 offers a summary overview of the different appropriation variations presented here, offering additional information with regard to the context of study and the unit of analysis typically adopted by existing studies. We note that, while some studies focus on the individual level, the majority focuses on organizational contexts where IT use is mandatory. We further highlight that while the previous discussion has highlighted their differences, the common denominator across all variations is that of the user making the IT their own, irrespective of the exact process adopted. In what follows we highlight the current shortcomings of the appropriation literature.

\subsection{Commonalities and Limitations in the Existing Appropriation Literature}

First, all variations recognize that how users use IT may be different from the originally designed instrumental use. This 


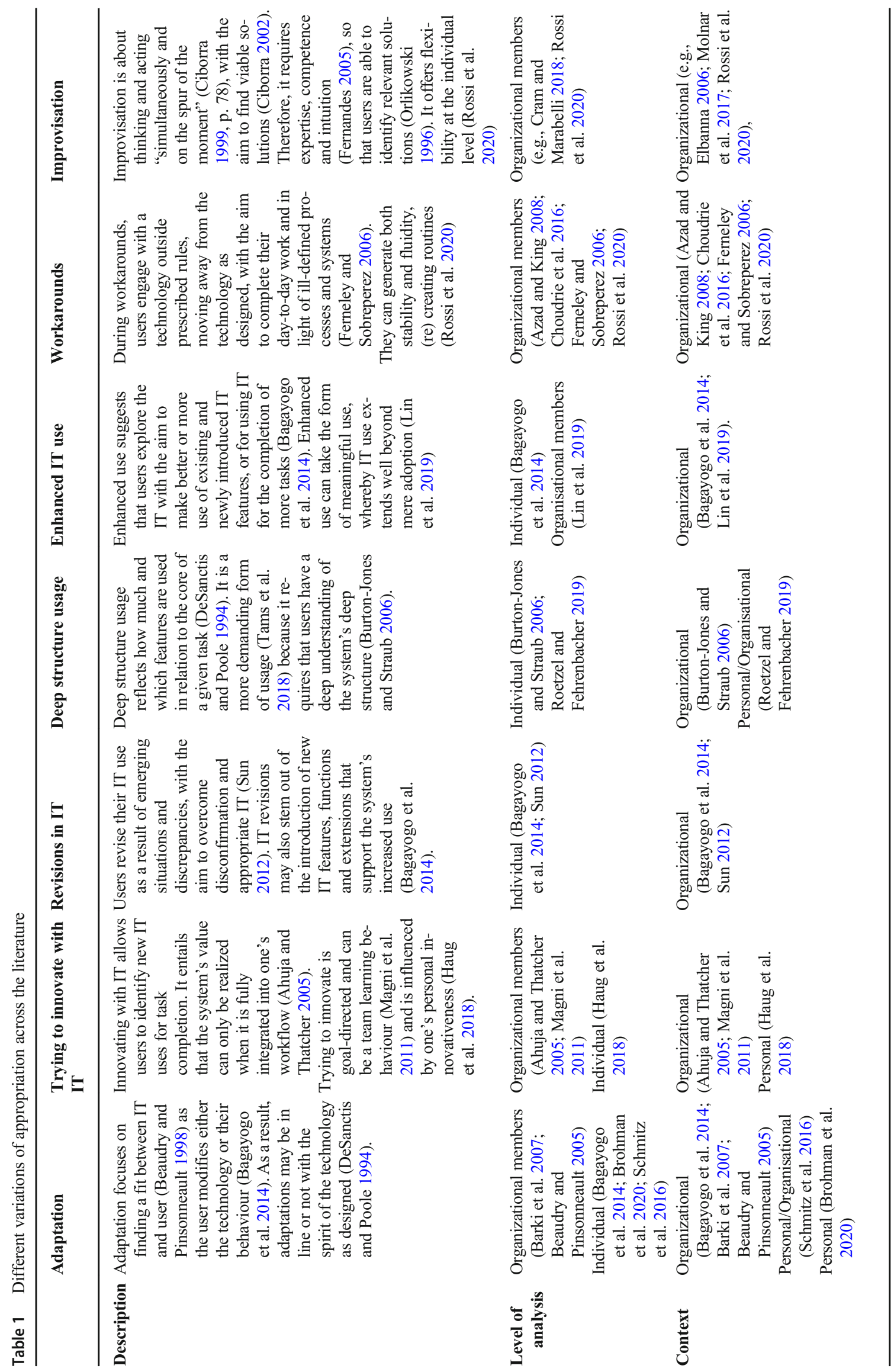


suggests that users move from 'technology-as-designed' to 'technology-in-use' by engaging with the technology, exploring its potential and modifying, eventually, its features as per their requirements, which is what leads to the appropriation of IT (Lapointe and Beaudry 2014).

Second, all variations are focused on identifying a fit among task, technology and user. This is done either by modifying the technology, the task, user behaviour or any combination of these. The assumption here is that a fit does exist and can be found by the user. However, a user may follow the same processes that are said to lead up to appropriation, without achieving the desired outcome, i.e., appropriation itself, eventually rejecting the IT. This possibility is under investigated in the existing literature.

Third, the extreme majority of studies focuses on enterprise-level systems and/or on organizational contexts (see Table 1). For example, improvisation studies focus on the improvisational capability of organizations (e.g., Chatterjee et al. 2015), or the improvisation acts of organizational members during fire-fighting situations (Alblas and Langerak 2015; Repenning 2001). Such an emphasis is expected considering that investments in enterprise software are costly (Bagayogo et al. 2014) and reluctance, or even failure, to adopt enterprise IT endangers performance and profitability. This assumes that users, while attempting to appropriate the IT, will prioritise the requirements of the organization over their own. It also assumes that there is a restricted set of IT systems which has been imposed top-down by the organization. As such, even when the unit of analysis is that of the individual, users are treated as organizational members with the assumption that their commitment to make things work may be low.

However, individual users under their volitional control, may proceed at their discretion with the appropriation of IT; in doing so, they may employ a multitude of adaptations and modifications, if and when required (Schmitz et al. 2016), without constraints imposed by a top-down hierarchy, they may not abandon the process when they identify a good enough solution, or abandon the process altogether should they consider that a tentative solution is either non-existent, or too difficult (Swann 1999). Further, under the user's volitional control, where a top-down description of what constitutes suitable use does not exist (Schmitz et al. 2016), the acts of adaptation, exploration, and appropriation can be more flexible and indeed lead to rejection without (fear of) sanctions; time and flexibility allow users to discover possibly unexpected usages that can increase their satisfaction with the IT artefact. As such, research should focus more on use contexts beyond the typical organizational so as to appreciate the richness of the phenomenon, how IT may be adapted when its use is not mandated and users are able to choose from a wider set of action possibilities.

\section{Method}

We seek to understand "what is the process of appropriation of IT devices by individual and volitional users following negative disconfirmation?" This research question entails a broad focus around post adoption use behaviour, but is squarely rooted on the discrepancies users experience between initial experiences and realities in use. This broad focus further allows us to consider the problems users may encounter while attempting to fulfil a task, and the different solutions they may enact with the IT device in question, or any other IT device at their disposal.

To address this question, we designed a qualitative study using Grounded Theory Method (GTM) techniques. GTM is often used for describing process-based phenomena, and offers data collection and analysis that support the emergence of theory from the data, while being guided by existing relevant theories (Urquhart 2012). We follow a bottom-up approach in line with the GTM paradigm (e.g., M. Barrett and Walsham 1999; Boudreau and Robey 2005; Volkoff et al. 2007), meaning that trial and error emerged from our preliminary analysis of the collected data, when we observed that users, first, had an expressed interested in using the tablet for various reasons and that failing to use it in an as-is fashion, they were trying out different things. This observation led us to proceed with subsequent data collection in order to identify either similar or dissimilar behavioural patterns, where the second phase of data collection was influenced by the concepts emerging from the first phase (theoretical sampling) (Urquhart 2012).

Our GTM study was designed specifically around the tablet and occurrences of negative disconfirmation with it, in order to capture the processes of appropriation following such occurrences. We chose to focus specifically on the iPad. The iPad, as an exemplar case of a tablet is particularly popular among users, offers a fairly consistent user experience across its numerous generations (Zamani et al. 2019), and thus allows for maximum similarly in the data, which in turns leads to generating and verifying basic properties and conditions for our core constructs (Urquhart 2012). For our GTM study, we followed the stages of analysis as proposed by Glaser (Glaser 1978) and Charmaz (Charmaz 2006) of coding and theorising around the open (or initial), selective (or focused) and theoretical codes, writing up memos and theorising around these, too, and finally, integrating and linking up our codes and core categories through a constant comparative method, finally developing our trial and error theory of appropriating. These are discussed in detail in the next two subsections.

\subsection{Data Collection}

When we began looking into the tablet and how users use it, we noticed that many bloggers were documenting their experience with the tablet in their personal blogs. Within them, the 
tablet users were offering narratives of their everyday life, sharing their goals and experiences with the tablet as well as detailed accounts of their interaction, the problems they were encountering and the employed strategies towards solving these. We therefore considered safe to assume that these bloggers were able to provide candid descriptions in their blog posts of their everyday interaction with the device, of the IT uses they were hoping or were successful in developing with the tablet, and of the actions that allowed them (or not) to appropriate it (Hookway 2008; Zamani et al. 2013).

The empirical material of this study therefore consists of blog posts. Blog posts often contain narratives of everyday life, where bloggers share their experiences and their goals with their readership. In our case, the collected blog posts are authored by iPad users who offer detailed accounts of their interaction, the problems they encountered as well as the solutions they implemented towards resolving them.

The material was collected in two stages; the first spans the period between March 2011-August 2012, and the second between January 2017-July 2017. The beginning of our study (2010) and our first data collection phase (March 2011 August 2012) overlapped with when the first tablets were introduced to the mass consumer market (i.e., the iPad). Further details on data collection can be found in Appendix 2.

During this phase, our preliminary data analysis showed that, while users were keen to identify a fit for the tablet into their everyday, the process was rarely straightforward. Instead, users exhibited a highly explorative behaviour, where they were trying different use scenarios, often incorporating the iPad into their device portfolio in novel ways. The use of GTM allowed us to identify negative disconfirmation as a fairly relevant conceptual category for our study, and where appropriation and rejection are outcomes of a trial and error process where the user tries out different things in order to identify solutions to this negative disconfirmation.

In light of this, we proceeded with a second phase of data collection (January 2017 - July 2017), following theoretical sampling of the same type. (Urquhart 2012). Our aim was to increase and verify the usefulness of each of the emerging categories and establish the conditions for each. As such, theoretical sampling for the second stage entailed focusing exclusively on sampling blog posts that would help us achieve meaning and content saturation (Hennink et al. 2017) while selectively sampling with the emergent core category in mind (Glaser 1978).

For both data collection staged, we examined the collated blog posts against our inclusion criteria. Namely, each blogpost had to: a) contain a rich description of the blogger's interaction with the $\mathrm{iPad}, \mathrm{b}$ ) describe voluntary use of the device for both personal and professional use scenarios, c) contain a description of negative disconfirmation i.e., the user attempted to use the device in a particular way but for some reason failed to do so, and d) describe an underlying effort to overcome disconfirmation. These criteria allowed us to collect material that contains contextual and processual information, supporting us in addressing our research question.

The chronological difference between the two stages means that, while during the first stage, the tablet was still a novel device, during the second stage, users had become directly or indirectly familiar with it, and had a clearer idea about their goals and expectations regarding the device as a result of others' experiences and advertising. However, the purpose of our study is not to compare and contrast expectations, where the 'starting point' of each experience would be undoubtedly critical. Instead, we are only interested in examining how users attempt to overcome negative disconfirmation through trial and error behaviour and regardless of the specificities of the technical features that prompted the disconfirmation. Therefore, we do not consider the different tablet generations as a critical element for our interpretations, precisely because the data reveal a consistent behaviour of trial and error across the different generations of the technology.

All in all, the final data pool consists of 136 blog posts, authored by 86 unique English-speaking tablet users (Table 4, Appendix 1). Of them, 76 bloggers are male, 96 are based in North America (USA and Canada), and the majority of the remaining blog posts are authored by Europe-based bloggers. Most users have managerial positions or freelance.

\subsection{Data Analysis and Interpretation}

We began our analysis with a preliminary examination of our data and moved to open, selective and theoretical coding following the Glaserian paradigm (Glaser and Strauss 1967) and in line with Urquhart's and Fernandez's recommendations (2013). While open coding, we coded, line by line, or at word level, and more rarely full paragraphs, often using in vivo labels and drawing from existing literature (see Fig. 1 for some examples). This was done by the first author in consultation with the second author, discussing the relevance of the used labels and the consistency of the coding. An overview of the process of data collection, analysis and interpretation can be found in Table 2.

The stage of open coding is critical as it acts as a sensitizing device for data collection and analysis, and for further examination of the existing literature (M. Barrett and Walsham 1999). Indeed, during this stage, we noticed that users were recounting some disconfirmation, most often than not, a negative one, with the tablet, following which they begun trying out different solutions in order to overcome it and address the experienced issues. In many instances, this led to further 'errors' in their interaction with the tablet. We moved to selective coding by focusing our coding around the codes that seemed to relate to the emerging categories, while identifying their variants, how they relate to each other (Hekkala and Urquhart 2013), drawing iteratively from the literature, 
Fig. 1 Examples of Open Coding Trial and Error Schema
"The conventional wisdom on tablets is that they're for consumption not production. You can absorb
text quickly and well, for example, but writing is a chore. In my experience, at least with the Apple
keyboard - the Logitech one is supposed to be better for typing but is also heavier - this view is
accurate.
The machine is capable from a performance standpoint, don't get me wrong. I used it over the week
for some light document editing, some basic spreadsheet work and a lot of email. But while typing on
the Apple Smart keyboard is fine, but I wouldn't want to write anything extensive using it.
There's a reason the words you're reading right now were written using the iMac in the office, not the
iPad Pro."
/Coded as the open code "writing is a chore"
Extract from blogpost "A week with an iPad Pro" (B11)

"At this point I don't think any working professionals are going to be able to go all-in on the iPad Pro as a their daily driver. There are just too many walls and ceilings to bump into right now. However, for a casual user, this device could very well be all that you need."

/Coded at "too many walls and ceilings to bump into"

Extract from blogpost "iPad Pro review" (B19) constantly reviewing and revising the evolving coding scheme (Wiesche et al. 2017). The descriptions of our codes and core categories can be found in Table 3 .

\section{Findings}

In this section we present our findings, organized around our three core categories of negative disconfirmation, trial and error and outcomes, in order to illustrate how negative disconfirmation emerges, the process of trial and error behaviour, and the conditions for each of the two main outcomes of this process. Inspired by other researchers (e.g., Korica and Molloy 2010; Vaast and Levina 2006), we use vignettes. Vignettes are often used for the presentation of findings as they constitute concrete examples, which are carefully selected as "illustrations and exemplars of particular concepts" (Swan et al. 2007, p. 1817), and in this case serve as a way to provide a rich description of different examples of trial and error behaviour without decoupling these from their

Table 2 Stages of Data Collection and Analysis

Stage Description of the Process

First Data Collection

Mar 2011 - Aug2012

Second Data Collection Jan 2017 - Jul 2017

Reporting of Findings
Familiarisation: Review of the empirical material: memoing and note taking, emergence of initial ideas (trial and error) Open coding: initial coding line by line, occasionally at word level (cf. Table 3)

Selective coding: open codes organised around core/initial ideas (trial and error), grouping codes together, primarily guided by the preliminary research question (cf. Table 3 ).

Reflection: Review of codes and themes. The coding scheme was reviewed by the first two authors to ensure it reflects the emerging themes, that codes are mutually exclusive and that they are exhaustive (Miles and Huberman 1994).

Negative disconfirmation emerged as particularly prominent. We examined theoretical saturation (not achieved) $\rightarrow$ A second data collection was decided on the basis of theoretical sampling to achieve it.

New data were collected, focusing specifically on negative disconfirmation occurrences, and a) newer generations of iPads, b) volitional contexts of use, where c) the iPad is used both for professional and personal use cases by similar types of users (boundary conditions), with a view to achieve meaning and content saturation of our codes (Hennink et al. 2017). This stage was guided by theoretical sampling (Urquhart 2012) and helped us achieve theoretical saturation.

New material was added in the main pool, and open coded line by line, or at word level.

Selective coding redone: integration of new selective codes, reframing of previous ones, identification of the properties and the components of the core categories (c.f., Table 3).

Reflection: The coding scheme was reviewed for consistency by the two first authors. Theoretical saturation was examined (no new themes emerging and the theoretical categories were saturated as a result of coding).

Theoretical Coding: reflective elaboration of relationships among categories (Glaser 1978) via constant comparison, using evidence from the data, building on our memos, on the basis of Glaser's coding families (Glaser 1978) and borrowing concepts from existing relevant theories (Alter 2014; e.g., A. K. Barrett 2018; Beaudry and Pinsonneault 1998, 2005; A. Bhattacherjee and Premkumar 2004; A. Bhattacherjee 2001; Carroll and Fidock 2011; Ferneley and Sobreperez 2006; Schmitz et al. 2016)

Final analysis of selected quotes, development of chains of evidence (Table 3), and integrative diagrams (Fig. 2), revisiting the literature and developing findings. 
Table 3 Descriptions of Categories, Selective Codes and Open Codes

\begin{tabular}{llll}
\hline Category & $\begin{array}{l}\text { Selective } \\
\text { Codes }\end{array}$ & Open Codes & Analytical summary (Memos) \\
\hline $\begin{array}{l}\text { Negative } \\
\text { Disconfirma- } \\
\text { tion }\end{array}$ & Goals & $\begin{array}{c}\text { "skeptical" (e.g., B5, B8, B78), "what always wanted the } \\
\text { iPhone to be" (e.g., B92), "primary machine broke }\end{array}$ & $\begin{array}{l}\text { Users begin interacting with the iPad, having some goal } \\
\text { in mind. This goal may be very tangible and specific } \\
\text { down/replacing" (e.g., B1, B40, B127), "IT experience } \\
\text { (e.g., replace a pre-existing IT (or not) device) or fuzzy }\end{array}$ \\
& $\begin{array}{lll}\text { (e.g., B109)" } & \text { and highly explorative (e.g., explore the potential of } \\
\text { the tablet). As such, negative disconfirmation seems to } \\
\text { be the result of unachievable goals, and gaps between } \\
\text { goals and realities in use. }\end{array}$
\end{tabular}

Comparing "comparing to paper" (B98, B99), "comparing to books" (e.g. B8, B62), "comparing to a laptop" (e.g., B11, B67, B101), "comparing to using it with mouse and keyboard" (e.g., B92, B123, B28), "none that I've tried work all that well" (B1)

Trial and Error Tentative solutions

Error

Outcome
Appropriating "At first, I used SimpleNote to sync with Scriverner. Eventually, I found a better solution, using Scrivener, Dropbox, and Elements. This last solution has worked well for me since I discovered it." (B67)

"Using a smaller keyboard" (B23), "to record notes during patient interviews, both by typing and with a stylus" (B99), used only while "at a table or another flat service [surface, sic]" (B67)

Non-tolerable errors: "lack of speed and accuracy" (B99), "[not] easy for me to mix and match my favourite instruments" (B23), "more fatiguing compared to pen and paper" (B55)

Tolerable error: "there wasn't enough power" (B23), "quasi-mobile device, but it's not recognized as one" (B115)

Rejecting "I gave up and borrowed laptops (one per continent) to do all of my posts, including when I was covering our keynotes at TNW Conference. (...) However, in the near future at least, I will haul my laptop on any trip I go on where I'll be blogging" (B1), "I will probably never try reading another book on the iPad again: destroying one of my greatest pleasures with constant discomfort seems like a ridiculous thing to do to myself again." (B11)
In setting their goals, tablet users may be influenced by reviews, advertisements, others' experiences as well as their own past experience with similar or dissimilar devices. Negative disconfirmation surfaces when the user is unable to achieve their goal (e.g., they are unable to read an e-book while lying in bed), and when they compare the tablet with other IT and non IT devices (e.g., comparing the iPad to the Kindle and physical books, and the resulting experience). It is noted that comparison is continuous: from the moment the user begins interacting with the tablet all the way to finally appropriating or rejecting it, and during their trial and error efforts.

Trial and error is what users go through in the face of negative disconfirmation in order to overcome it. They do so by adapting the device e.g., using external add ons), augmenting it by using third-party applications, and even adapting their tasks and workflows. This behaviour is influenced by the user's experience with IT, and prior experiences, and this being a tentative solution suggests that a) it is one of the many possibly equivalent solutions towards overcoming negative disconfirmation, and b) it is later reviewed for its applicability and can potentially lead to further problems (errors).

Errors denote problems stemming as a result of the tentative solutions (being not good enough or raising further problems that prohibit the user from achieving their goals). As a result, disconfirmation persists or intensifies.

- There may be non-tolerable errors, where the tentative solution is not good enough or a solution does not exist.

- There may be tolerable errors or no errors (the tentative solution does not impede further interaction and use).

Appropriation surfaces as the user transitions to new workflows, by adapting their tasks and their behaviour to the tablet's requirements, or equally employing tentative solutions that augment the tablet (e.g., hardware or software add ons) and produce no errors or only tolerable errors. This suggests that the user overcomes negative diconfirmation and achieves their goals, and that the user integrates the tablet into their everyday.

Users reject the tablet because they cannot overcome negative disconfirmation: they continue comparing the new to the old way of completing tasks, and they either deem the tentative solutions as not good enough or the errors as non-tolerable. As a result, they often regress to their old routines. 
Table 3 (continued)

\begin{tabular}{|c|c|c|c|}
\hline Category & $\begin{array}{l}\text { Selective } \\
\text { Codes }\end{array}$ & Open Codes & Analytical summary (Memos) \\
\hline & $\begin{array}{r}\text { Identifying } \\
\text { Benefits }\end{array}$ & $\begin{array}{l}\text { "face the congregation at all times" (B105), "wonderful } \\
\text { opportunities for "social" internet surfing" (e.g., B80, } \\
\text { B11), "a screen that connects me with people" (B17), } \\
\text { "Once you get used it that, you realize how efficient } \\
\text { you are with the lack of distraction." (B81) }\end{array}$ & $\begin{array}{l}\text { The outcome of appropriation as a result of the trial and } \\
\text { behaviour is subject to the user identifying benefits in } \\
\text { using the tablet: identifying benefits is a condition for } \\
\text { the appropriation of the tablet. Some of the benefits is } \\
\text { the use of the device together with others, without } \\
\text { isolating themselves from their environment, and } \\
\text { without hindering their social interactions. Identifying } \\
\text { benefits allows users to develop their personal use } \\
\text { cases, persevere in finding a tentative solution and } \\
\text { evaluate overall more favourably the tablet despite } \\
\text { initial disconfirmation. }\end{array}$ \\
\hline & $\begin{array}{l}\text { Feeling } \\
\quad \text { restricted }\end{array}$ & $\begin{array}{l}\text { "too many walls and ceilings to bump into" (B19), } \\
\text { "Apple will sit and control what you can do with the } \\
\text { advice" (B111), "the size of the device doesn't let } \\
\text { much freedom for taking many photos" (B109), } \\
\text { "inability to listen to a video in the background" (B17) }\end{array}$ & $\begin{array}{l}\text { The outcome of rejection is more likely when users feel } \\
\text { as if the tablet restricts them in some way. Missing } \\
\text { features and functions entail that the user either will } \\
\text { have to work around them (tentative solutions), or } \\
\text { accept them (tolerable errors). If this is unacceptable } \\
\text { though (a tentative solution does not exist or the error } \\
\text { is non-tolerable), the user feels as if the tablet is } \\
\text { designed in a way that restricts their activity, especially } \\
\text { when compared to other devices. }\end{array}$ \\
\hline
\end{tabular}

Note: numbers in brackets denote the ID number of the blog post. The complete list can be found in Table 4 in Appendix 1

contextual conditions. We chose the particular vignettes because they are rich descriptions of negative disconfirmation, trial and error and outcomes, but also show the variety of contexts within which users tried (and possibly failed) to appropriate the iPad.

\subsection{Negative Disconfirmation}

Through the analysis of our findings, we see that initial negative disconfirmation with the tablet surfaces in indicative different contexts of iPad use, as a result of a discrepancy between the user's expectations and goals in using the tablet and the tablet's actual performance. Below, we present two vignettes to illustrate how negative disconfirmation surfaces.

\subsubsection{Vignette 1: Using the iPad as a Replacement}

Dale (B1) acquired an iPad with the aim to use it as his sole device while travelling for work-related purposes. He is a frequent flyer and he was motivated to use the iPad as a result of his battery capacity and light-weight format, that could allow him to be more mobile and remain productive for longer while on the go:

"The two most important factors were that the iPad has a killer battery (10+ hours no matter what I'm doing) and that it is slim and only 1.5 pounds. Compare this to my $6+$ pound and well over one inch thick laptop that gets at best 5 hours of use (on a 9-cell battery) - basically I bought the iPad in part to be used as my travel laptop replacement for these reasons" (B1).

With this in mind, he expected that the iPad could serve him well while covering conferences around the world. However this was not the case. Dale explains that, despite of its strong points, the iPad did not perform as expected and that it could not function as the sole device. The iPad did not fit well with his workflow because it did not allow him to complete important tasks as part of his job, which results in his negative disconfirmation and him using other devices in order to keep up with his duties:

"I took notes at the DC conference on the iPad, which turned into three posts. However, and here is the main moral to this post - all these posts came at best hours after the sessions because I didn't actually post any of these stories to WordPress using the iPad. (...) So to make a long story short, I gave up and borrowed laptops (one per continent) to do all of my posts, including when I was covering our keynotes at TNW Conference." (B1).

\subsubsection{Vignette 2: Using the iPad Exploratively}

Gordon (B11) purchased the tablet with the aim to explore and experiment with it while recovering after his operation. Contrary to Dale, Gordon does not have a clear goal with 
regard to his tablet use. Instead, he clearly notes that he was motivated to acquire it for two main reasons: the first was his prior experience with his iPhone, and the second his desire to find out about the iPad's merits and potential:

\section{"I bought an iPad last week because I love my iPhone so much (...) and also because I figured that, since I was going to have a lot of time on hands recovering from my surgery, it would be fun to have a cool new toy. (...)” (B11).}

While the goal is not as specific as in Dale's case, Gordon similarly compares his tablet experience to his experience with other IT and non-IT devices, and notes that the tablet performs less satisfactorily, in part due to its form factor:

"The first day I had it, I rented a movie I have always loved, MOVIE_1234, ${ }^{1}$ and tried to watch it for over an hour before simply giving-up. (...) A laptop, buy [sic] the way, would have been much easier because you can adjust and hold the angle screen more easily." (B11).

Based on the collated narratives, we see that users acquired the tablet with the expectation to either use it within an occasionally well-defined use scenario (Vignette 1) or experiment with it in an attempt to explore its potential (Vignette 2). In both cases, negative disconfirmation ensues a comparison. First, users assess the tablet's success in helping them achieve their goals and meet their expectations, and compare how they used to complete tasks and other activities with their other IT and non IT artefacts to how their workflow changes by using the tablet instead. Further, regardless of whether users acquired the tablet for exploitation (vignette 1) or exploration (vignette 2), negative disconfirmation denotes that the IT artefact fails to meet the user's goals and expectations.

\subsection{Trial and Error}

Trial and error is a sequence of attempts to bridge the gap between goals and actual experience, and while the user tries out one or more tentative solutions, in order to overcome their negative disconfirmation. The following vignettes illustrate trial and error behaviour, where iPad users try out different tentative solutions with the aim to tackle their initial negative disconfirmation.

\subsubsection{Vignette 3: Trying to Use the iPad as a Live Keyboard Rig}

Peter (B23) is a musician and music editor who has been using his MacBook Pro and a specialist application (MainStage) to emulate "the sounds of pro keyboards like Roland RD pianos

\footnotetext{
${ }^{1}$ The name of the movie has been redacted.
}

and synths when playing live". He is now interested to see if an iPad-centred setup can work equally well for live performances, and therefore replace the laptop. To do this, Peter needs to use "a decent "real" MIDI controller keyboard", but, to his disappointment, on the one hand, "iPads have neither USB nor MIDI inputs", while on the other hand, such larger keyboards typically requires an external power source (negative disconfirmation). To overcome this, he turned to an adaptor for connecting a keyboard to the tablet that uses the iPad as a power source (tentative solution).

While " $[t]$ his worked well, and the iPad was able to power the keyboards for hours", Peter "encountered a small glitch when [he] first plugged in [his] MIDI controller", when his tablet showed an error message that "there wasn't enough power" (tolerable error). However, he felt confident that this "was meant to work"; therefore he "started experimenting" (trying), and discovered that the error was due to the sequence of plugging in cables and adaptors. He next raises the issue of latency as there is a delay between him stroking a key and receiving a response from the tablet. This is however "hardly noticeable, or unnoticeable" (tolerable error) and although he does "have the occasional problem (error) [ ...], resetting the iPad makes it responsive again" (tentative solution).

To better control sounds and effects, Peter had to map the keyboard on the iPad application. Yet, while comparing the iPad-centred versus the MacBook Pro-centred set up, he explains that "there doesn't seem to be a way of mapping all of those useful buttons, knobs and sliders on my keyboard to do anything useful" (negative disconfirmation). After further attempts (trying), he arrives at the conclusion that this is a limitation of the application rather than of the keyboard (no solution).

\subsubsection{Vignette 4: Trying to Use the iPad for Patient Care}

Michael (B99), a medical student during his clinical year, has been finding the tablet both useful and versatile for his studies and patient care. While at the hospital, he needs access to medical records that are stored securely into a dedicated content management system. However, he was not able to access this system directly from his tablet (negative disconfirmation). To overcome this obstacle, he tried out using the Citrix receiver, a freeware desktop-virtualization package (tentative solution). This allows him to access the centralized host and to "tap into [the] EMR ${ }^{2}$ system" (no error).

However, " $[t]$ here are some ways where [he's] been less than impressed with iPad". Michael notes that the iPad is "not a very good input tool" due to the "lack of speed and accuracy" in capturing information while talking to his patients (negative disconfirmation). He has tried "to record notes during patient interviews, both by typing and with a

\footnotetext{
${ }^{2}$ EMR: electronic medical record.
} 
stylus" (tentative solution), but he doesn't consider this set up as satisfactory because, while being "too busy making sure that the [...] notes [a] re accurate", he feels the tablet is a barrier between the patient and himself (non-tolerable error). In addition, he compares the tablet to a regular notepad, and deems that " $[p]$ aper and pen is still superior in a lot of cases".

\subsubsection{Vignette 5: Trying to Use of the iPad during Client Meetings}

Harriett (B55) is a litigator and a consultant who switched from the iPad mini to the iPad Pro, with the aim to see if she could "be doing more with [the] iPad" while on the go and while meeting clients. She begins her narrative by saying that the iPad mini "has never been [her] preferred device [...] [for] productivity related activities", such as preparing presentations, legal briefs and the like. She considers that the larger form factor and the recently made available multitasking features have made "these types of tasks easier [...] than they ever were before". However, she describes her personal experience as a "compromise" when compared to her laptop experience.

She suggests that "the biggest problem with the iPad Pro was it was just too darn big". She could only use it "at a table or another flat service [surface, sic]", and being almost as big as a laptop, carrying the iPad Pro required some effort:

\section{"It wasn't something that could be thrown in a purse and taken on a whim [...]. If I was going to go the trouble, I personally would have preferred to have my Mac" (negative disconfirmation).}

Harriett reflects meeting with clients and describes "typing directly on the glass [as] a clunky experience" (negative disconfirmation). She considered pairing an external keyboard (tentative solution), but in her opinion this would make the tablet even more similar to a laptop, where there'd be a physical barrier between her and her client, which is "the situation [she] was trying to avoid by using the iPad in the first place" (non-tolerable error). She further compares note taking on the iPad with a stylus to note taking on a notepad and describes the former as "more fatiguing compared to pen and paper due to having less friction and having to apply more pressure to control the pencil" (non-tolerable error).

\subsubsection{Vignette 6: Trying to Use the iPad as a Primary Device}

Russ (B119) is a design professional who uses the iPad as his "primary machine", having been a Windows user for years. He had been unpleasantly surprised in the beginning. Due to his profession, he often has to import pictures and videos from his camera to edit them on his devices. However, he quickly realized that he cannot import these files from the camera's $\mathrm{SD}$ card to the iPad (negative disconfirmation). To overcome this obstacle, he tried out a camera connection kit (tentative solution), which seems to be working well (no error).

However, with regard to image editing, Russ notes that "the biggest issue is image resizing [...]. I've found it impossible to resize an image to a specific pixel value without also having to calculate the height value too"] (error). He has attempted to find an easier way around this, but after trying out different third-party applications (tentative solution), none of which seems to work (non-tolerable error). Despite that such problems require him to employ "cumbersome methods to achieve the desired results", his productivity has not decreased as a result of him using the iPad as his primary device.

These vignettes (3-6) illustrate that users apply a tentative solution so as to try and overcome their initial negative disconfirmation. Following this, users may be faced with further issues, namely tolerable (Vignette 3 ) or non-tolerable errors (vignettes 4, 5, 6), which prompt subsequent trials, until users identify a good enough solution or consider that no solution exists. Equally they may be faced with no errors (vignettes 4, 6 ) at all, when the applied tentative solution is considered a good enough one.

In what follows, we describe appropriation and rejection as the two major outcomes of trial and error, and we discuss the conditions for each outcome.

\subsection{Outcomes of Trial and Error: Appropriation and Rejection}

Through trial and error behaviour, users move from tentative solutions to good enough ones, that help them overcome negative disconfirmation. In such cases, these solutions entail the adaptation and modification of the technology, where the user augments the tablet with e.g., external keyboards (vignette 3 ), specialized applications (vignettes 3, 4, 6), and adapts and modifies their own habits and routines (vignettes 6). In doing so, the outcome of trial and error may be the appropriation of the IT artefact or its rejection. In the vignette that follows, we illustrate the outcome of appropriation and highlight its conditions.

\subsubsection{Vignette 7: Appropriation and its Conditions}

Garry (B120) has been an iPad user for some time. During this time, he has moved much of his work his MacBook Pro and iMac to the iPad. He notes however that, "there were a few things [he] needed such as a keyboard case, writing app, etc." in order to do so. In his blogpost, he takes his readers through his journey of how he chose his current set of applications, as well as how he augmented his tablet with an external keyboard that makes him feel "like typing on a Macbook Pro" while offering "multiple viewing angles like a laptop". He chose 
these solutions as a result of trial and error, like all other users, and he further explains that while he "had no problems finding those things, the real challenge was in changing [his] OS $X$-centric mindset". This entailed "unlearn [ing] some of [his] long-time habits" and "judg [ing] iOS on its own terms rather than constantly comparing it to $O S X$." As a result, Garry notes:

"The iPad is a more personal experience and I tend to
have it with me wherever I am in the house. (...) Since I
got my iPad Air 2, I have hardly even picked up my
iPhone 6 Plus when I'm in the house. And the iPad
has cut down the use of my iMac drastically, and mostly
left the desktop computer relegated to work duties.
Don't get me wrong, I still love my iMac and iPhone 6
Plus, but neither of them can compete with the iPad Air
2 for certain uses such as games, reading, comics, etc."

Garry recognises that the iPad can be of value to him, offering a more personal experience, and specifically for some activities such as reading and gaming. To "narrow the absorption gap" (Clark 1987, p. 156), he has opted for an external keyboard and applications, such as the Kindle app, which enable him to support these practices (Carroll and Fidock 2011).

Similarly to Garry, Russ (vignette 6, B119) has also appropriated the device. He has migrated to the iPad almost the entirety of his computing activity by adjusting his habits and routines as well as modifying the device itself through add-ons: "There are a few areas, such as image resizing, which it severely lacks, but there are cumbersome methods to achieve the desired results on the tablet." In Russ' case however, the reason for being motivated to identify these "cumbersome methods" and to employ them on a daily basis, has been the increase of his productivity as a result of the lack of multitasking:

"it's lack of side-by-side apps (i.e the traditional Mac OS X setup) means you actually end up focusing more on the work in hand, because there's nothing that's distracting you across the screen."

Going back to the definition of appropriation, the stories of Garry and Russ clearly illustrate that, appropriation of the tablet suggests that the users make the technology 'their own', despite their initial negative disconfirmation, specifically because they identify some benefit in using the IT artefact (Carroll and Fidock 2011; Clark 1987). Russ, for example, having been disappointed that the tablet doesn't allow easy image editing, explains that it is now his preferred device because it has increased his productivity, as it offers a more focused interaction, without distractions.
As users learn how to use the new IT device, identifying some beneficial use is of paramount importance and is the tipping point for eventually appropriating or rejecting the device. In those cases that users are unable to identify any benefits in using the iPad, or when such benefits come with sacrifices users are unwilling to make, the outcome of the trial and error behaviour is that of rejection.

\subsubsection{Vignette 8: Rejection and its Conditions}

Rejection suggests that the tablet cannot support the user in meeting their expectations and achieving their goals. This may mean that the tablet cannot reasonably substitute a previously owned IT or non-IT artefact or that it doesn't improve one's workflow in some way. One's golas and their experiences with other forms of IT, and even with non-IT solutions (e.g., pen and paper), have an impact on how an interaction is experienced because they weigh in in how users make sense and act about technology (Kendall et al. 2020; Orlikowski and Gash 1994) and is quite applicable when rejecting the iPad.

Harriett (B55, vignette 5) acquired the tablet in an attempt to uncover new IT-centred use scenarios. Without a specific use in mind, she suggests that the large form factor of the iPad was the main issue that caused her negative disconfirmation, and for failing to integrate it in her everyday workflow. Its size meant further constraints in relation to portability, ergonomics and connectedness with clients, all of which were obstacles to her productivity. The tentative solutions she identified could only intensify her negative disconfirmation and lead to further errors. As such, she was unable to identify any benefit in using the device as she considered that her past practices of using e.g., a legal notepad, posed fewer restrictions. This resulted in her returning the tablet. Another user, Dwayne (B64), similarly to Harriett, notes that the restrictions he was faced with while using the tablet, exceeded by far the benefits he was able to identify. Even though he was "positively surprised by the Ipads capabilities" as far as battery life goes, he was not that impressed by the fact that, as a Linux user, he was unable to access iTunes, which would allow him to load all he needed to the iPad.

It is interesting to note however that, rejection and appropriation seem to exist along a continuum, rather than being binary outcomes of trial and error. For example, Michael (B99, vignette 4), having been using the tablet for different usages, considers the device "invaluable", because it allows him to take stock of every possible moment while at work. But he is less content when it comes to how the tablet has been serving him during his rounds because the tablet acts like a 
barrier between him and his patients, which he consider as a restriction and prioritises ultimately achieving a better communication with the patients rather than his convenience ("Who wants a medical student (someday physician) who focuses more on a computer than on the person?"). As such, while the iPad enables new usages and offers some benefits (e.g., studying while on the go, accessing information), it does lead to lead to ineffective practices, too, thus he "put [s] away the iPad" when being with patients. In other words, through Michael's example we see that users may appropriate the device for some use scenarios (in this case, accessing health records while on the go), but reject it for others.

Therefore, the conditions under which trial and error leads to rejection rather than appropriation, have to do with perceived restrictions, and the extent to which these restrictions seem to balance out any potential benefits. In such instances, the perceived restrictions are the reasons for gaps between goals and reality, i.e., they prohibit users from using the tablet according to their initial goals. This is particularly clear in Harriett's case who notes that, while she could augment the tablet in a way that would allow her to use it as desired, doing so would outweigh the benefits she was after (portability and flexibility).

\section{Discussion}

In this study, we focused on the volitional use of IT in order to understand if and how users overcome initial negative disconfirmation, and why some users appropriate the IT artefacts, whereas others fail or refuse to do so. Drawing from grounded theory method techniques, we have identified two core categories, trial and error, and outcomes, whereby trial and error is observed following negative disconfirmation, and the iterations of trials and errors result in either appropriating or rejecting the IT artefact. Fig. 2 offers an illustration of how the core categories (trial and error and outcomes) have been build up on the basis of their relationships. As the figure shows, trial and error is composed of feedback loops (iterations), where a preliminary tentative solution may lead to different types of errors (tolerable, non-tolerable errors) or, indeed, no errors. When the feedback loop 'breaks' (dashed line), trial and error leads to the outcomes of appropriating or rejection, depending on the conditions. If, through trial and error and despite the experienced errors, the user has managed to identify some benefits, the most probable outcome will be that of appropriation. Alternatively, if the user perceives being restricted, and especially if the experienced errors are deemed as non-tolerable, then the most probable scenario will be that of rejection. What is interesting and begs consideration is that trial and error takes place against the backdrop of constant comparison, whereby the user is comparing the new against the old workflow, their new to their old experience, and ultimately the iPad to other artefacts, which are not necessarily IT (e.g., comparison may entail comparing reading a book on the iPad versus reading an actual hardcover book).

Trial and error has been quite an influential concept, first appearing in the $1890 \mathrm{~s}$, when behaviourists observed that consecutive efforts (trials) help overcome an obstacle or solve a problem (Costall 1993). Shirahada and Hamazaki define it as "the process of continuous knowledge creation and acquisition until success is achieved" (Shirahada and Hamazaki 2013, p. 1108). Rerup and Feldman draw attention to the fact that people compare outcomes to targets, and then revise their routines as necessary so that they can meet those targets (Rerup and Feldman 2011). Indeed, as our
Fig. 2 Connecting trial and error to outcomes following negative disconfirmation

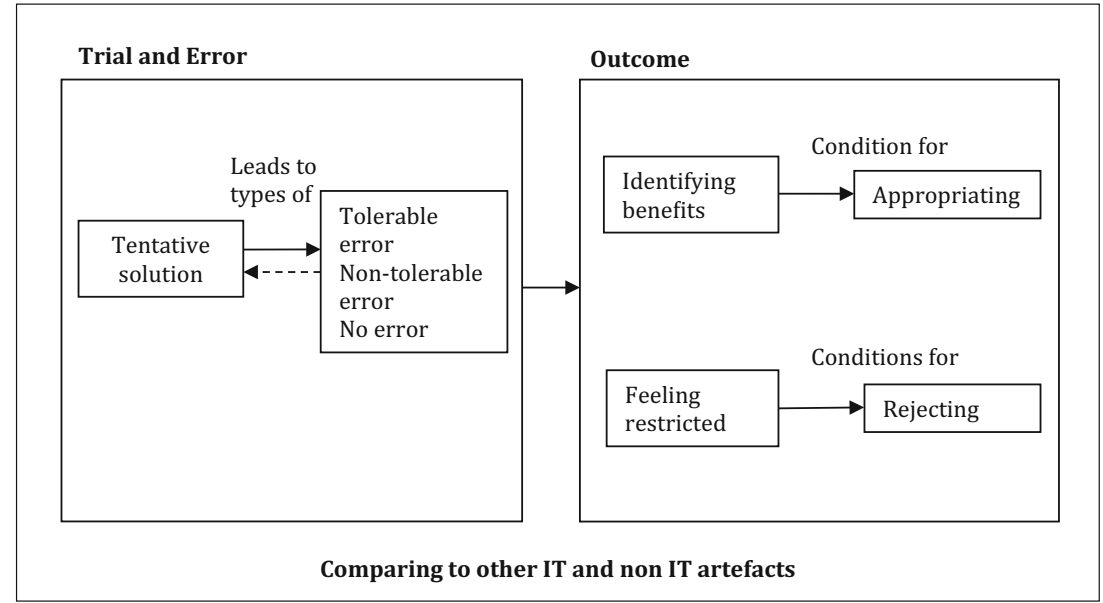


findings show, as the majority of users have an expressed interest in integrating the tablet in their workflow, upon experiencing negative disconfirmation they proceed with trying out different things in order to overcome it. In doing so, they combine and recombine their available IT devices and objects, in order to identify ways to 'make technology work'; when they are successful in this endeavour, they transition from the 'technology as designed' to the 'technology in use' (Elbanna and Linderoth 2015), which echoes existing conceptualizations of appropriation (Ahuja and Thatcher 2005). However, when they are unable to identify ways to make IT work in line with their goals, then the iterations of trial and errors lead to rejection instead of appropriation. As a result, trial and error may be observed when users are faced with anomalies and try out new things to overcome problems (McGann and Lyytinen 2008).

We consider trial and error to be a useful concept to discuss voluntary adoption of IT. Our findings show that, as users begin their interaction with the IT artefact, they are required to update their perceptions, exploring what they can do with the IT and how they can do it. Previous studies have found that users may adapt themselves (i.e., changing their routines), or the IT artefact (i.e., using external devices, additional applications etc.), or any combination of the two (e.g., Barki et al. 2007; Beaudry and Pinsonneault 2005), in their endeavour to see what actions are possible (Bagayogo et al. 2014; Sun 2012). Equally, it may be argued that the observed iterative attempts to identify and apply tentative solutions are nothing more a variation of the adaptation cycles, proposed by Sun in his seminar paper regarding user revisions of technology (Sun 2012). These iterative attempts in assessing tentative solutions are in turn reminiscent of the body of work on workarounds (e.g., Choudrie et al. 2016; Ferneley and Sobreperez 2006; Koopman and Hoffman 2003), as they entail that users tweak in subtle and less subtle ways the IT artefact, incorporating bundles of applications and other fixes (Choudrie et al. 2016; Ferneley and Sobreperez 2006; Koopman and Hoffman 2003). There are fewer similarities between trial and error and improvisation. Trial and error is primarily based on exploitation; as our findings show, tablet users seek to implement tentative solutions based on what they know and their experiences. In contrast, existing literature suggests that when improvising users tend to be more exploratory (Scheiner et al. 2016). Further, as improvisation is generally timesensitive (Pavlou and El Sawy 2010), users may be able to pursue a limited number of iterations. Yet, as our findings show, users may proceed at their discretion with as many trials they want or need to identify tentative solutions; it is telling that some users (Peter, vignette 3) pursuit several iterations of trial and error, whereas others (Harriett, vignettes 5) are less committed in identifying a solution. As such, echoing prior literature on trial and error, we posit that the only event that seems to stop the iterations is the identification of a good enough solution (Miner et al. 2001; Rerup and Feldman 2011) or the belief that a solution may not exist (Swann 1999). We thus consider that trial and error can function as an umbrella concept, consolidating essentially the different appropriation variations, specifically for the study of volitional use of IT devices.

At the same time, however, trial and error does not assume a priori that appropriation will be the only possible outcome. Our analysis shows that despite all users' expressed intention to integrate the tablet into their workflow (Vignettes 1 and 2), some of them were unable to find a good solution that can help them overcome their negative disconfirmation. Therefore, trial and error, despite its problem-focused and solution-focused nature, and in contrast to existing appropriation variations, does not assume that there is a fit between user, task and technology, which eventually will be achieved. Instead, trial and error can be an open ended process which may result to the simple abandonment of the device. This contribution is further supported by our findings if we consider that our analysis showed that appropriation and rejection exist along a continuum, whereby a user may appropriate the tablet for certain tasks, and reject it for certain others. Indeed, as in Michael's case (vignette 4), trial and error may lead to partial appropriation (or indeed partial rejection), if the user considers that the tablet is inappropriate in some way within a particular context of use, but at the same adequate or ideal for others. This challenges the rationalist view of technology, whereby adoption, rejection and behaviours in between are mostly seen as decision situations (Riemer et al. 2012), and further highlights the socially constructed and co-constructed nature of technology (Leonardi and Barley 2010), where the technology and its use evolve together (Richter 2009).

This draws attention to the conditions for each outcome. First, the essential component of appropriation is the identification of benefits (Carroll and Fidock 2011; Clark 1987). These benefits motivate users to persist in identifying and trying out different tentative solutions despite their negative disconfirmation. Such benefits may relate to productivity, performance, and convenience among other things (Dang et al. 2020), all of which are directly related to the needs and wants of the individual user. In light of this, Wyatt (2003) posits that individual users are more likely to adopt some kind of a technology if they consider that there are some benefits in its use, and 
they will only do so, if those benefits significantly outweigh any risks that use may entail (e.g., time wasted). Indeed our findings clearly show that time savings, and increases in productivity are deemed simply not enough in light of other sacrifices (such as lugging around a heavy object, being unable to focus on the primary activity or to properly interact with others), then the outcome of the trial and error behaviour is that of rejection (Michael and Harriett, vignettes 4,5), where the user discontinues its use for some or all tasks. This suggests that the tablet as an IT artefact is not defined or interpreted by its functions and the included or excluded features in its design; instead, users assess it in relation to more practical terms (i.e., if, how, when it can support them) and on its potential place within their wider sociomaterial practices (Kendall et al. 2020; Riemer and Johnston 2013).

\subsection{Theoretical Contributions}

Our theory of tablet appropriation through trial and error accounts for some of the shortcomings that presently exist within the IT appropriation literature. Specifically, by casting a wide net around negative disconfirmation and focusing on cases of tablet users with an expressed interest to incorporate the tablet within the constellation of their pre-existing IT devices, we have identified how and why trial and error may result in the appropriation or the rejection of the tablet. The use of such devices is often volitional rather than mandated, and thus, users can freely abandon the device if they consider that other options are better. In contrast, existing studies that focus on some type of appropriation appear to do so with an underlying assumption that eventually users will be able to identify a fit between the task, the technology and their work practices, through modifications, adaptations, workarounds and the likes. However, this constricted lens often excludes the possibility that such a fit may not exist, and that therefore, despite efforts to appropriate the IT device, users may eventually reject it. Our theory of trial and error manages to holistically account for both possibilities and explain their conditions within a volitional, individual use, which is a somewhat neglected aspect of IS use, despite the ubiquity of tablets.

In light of this, we consider that our trial and error theory further contributes to work done by Schmitz et al. (Schmitz et al. 2016) in relation to malleable IT and adaptation behaviours in two ways. Like the adaptive structuration theory they propose, our theory addresses voluntary use of IT for both personal and professional use contexts. Both approaches uncover rich use scenarios, iterative, exploratory and exploitive behaviours, and numerous types of adaptions and modifications that can be combined with each other toward achieving appropriation. However, we extend this work by formally incorporating the possibility for the rejection outcome.

Our second contribution relates with the characteristics of this trial and error process. Contrary to organisational systems, such as Enterprise Resource Planning (ERP) systems, contemporary devices are quite heterogenous in that they can fulfil a number of professional and private usages. While this heterogeneity may influence appropriation in a positive way it can also have a negatively affect if the learning costs are high. Relatedly, devices such as tablets, smartphones and the likes, are platform-based devices, anchored to an ecosystem of complementors, apps and users. A user may benefit by others' trial and error learning (e.g., through their blogposts and forum comments) and, equally, by the availability of hardware extensions and software apps, all of which may expand their usability options and help them identify new usages. We also note that trial and error with devices within a volitional context of use is not typically conditioned by external stakeholders who could otherwise enforce temporal, and other restrictions on IT use. As a result, trial and error is an iterative behaviour that may continue unobstructed up until the point where the user feels either content or too disheartened to carry on. Finally, at its core, trial and error has the comparison of task completion with or without the particular device, which is often used as a means to halt trial and error (and move towards rejection), or move towards appropriation.

\subsection{Practical Implications}

Studying how users use IT artefacts when technology falls short holds great potential for IT designers, manufacturers and organisations because it opens up a window into why and how users appropriate or reject the said artefacts. At the moment, there are numerous IT devices in the market, competing for consumers' attention by promising increased productivity and performance, on top of a pleasant user experience. However, not all of them prove to be as successful. As technology becomes more and more consumerised, personal devices are used for both personal and professional use scenarios (Dang-Pham et al. 2019) and such is the case with devices like the tablet. Users are able to exert increased control over IT adoption and use, because, within volitional contexts of use like Bring-Your-Own-Device schemes and consumerised environments, they can make their own choices (Doargajudhur and Dell 2019; Hovav and Putri 2016). They are thus able to abandon one IT artefact for another, which may offer a better workflow or may simply be more familiar with it. 
Our findings can be used by IT designers, manufacturers, practitioners as well as marketers to develop interventions and provide incentives that will facilitate appropriation over rejection. For example, designers could aim at alleviating feelings of being restricted by offering additional connectivity means or reducing existing barriers. Equally, marketers and organisations could develop interventions for highlighting and maximising the identification of benefits of using a particular IT artefact, especially when there are concerns in relation to a competitor and potential losses from switching.

In conclusion, in a world where the success of an IT artefact depends on continuous use and its appropriation and integration within one's workflows, our study offers an opportunity to better understand how individual users succeed or not in appropriating the tablet. Most importantly, it lays the foundations for future studies by offering a grounded-on-the-data theory that can be applied within our other contexts.

\subsection{Limitations}

Our study comes with limitations. While focusing on user behaviour post negative disconfirmation, we have not addressed its impact on a more holistic level so as to consider user experience and satisfaction. These concepts hold great significance for the design of IT and can possibly influence the benefit-driven nature of the user (Wyatt 2003), where such benefits may be more intangible. A second limitation stems from the nature of our empirical material and our methods, both of which are greatly influenced by the study's context and particularism (Davison and Martinsons 2016). Our analysis builds on blog posts; as such, the pool of our users represent an intersection of tablet users and bloggers. In addition, these users are authored by mostly male, North America-based iPad users, who hold upper-level managerial positions or are freelancers. This means that our findings are specific to the boundary conditions of this particular demographic. To an extent, this group may be considered homogeneous. However, this is far from the truth. Several studies to date have shown that cultural values and national cultures play an important role in how people choose and make use of IT, from using online social networks to smartphone devices and applications (e.g., Chu et al. 2019; George et al. 2018; Gupta et al. 2019a). Lastly, as evident from our findings, users have at their disposal a number of IT devices, and can thus afford to use either one of them, depending on their desire and preference. Therefore, our findings should be treated with caution, since they reflect chiefly interactions of generally affluent professionals who afford to experiment or 'play around' with IT devices that are fairly expensive.

\subsection{Future Research}

In this study, we have developed a theory of trial and error when users respond to moments of negative disconfirmation. Using GTM, we illustrated the trial and error process that users go through when exploring whether and how a new IT artefact fits within their personal and professional lives against the context of a larger portfolio of multiple IT artefacts. We have developed our theory from the ground up, where trial and error emerged as a process directly from the data.

We consider that the first step should be the validation of our theory across other contexts, including different IT devices and different users. In our study we have focused within the volitional context of use. However, given that tablets are actively being used within organisations and issued as corporate devices, it would be interesting to explore how the findings from this research may apply when the users are the employees of an organization and IT use is mandated; organizational culture would be an interesting concept to explore (Gupta et al. 2019b; Scheibe and Gupta 2017).

In addition, it would be interesting to investigate how trial and error may unfold when users are less affluent, and restricted to use one particular device only. In addition, because of the importance of cultural values in IT use, future studies should look into underlying differences across nationalities and/or ethnicities, focusing on the role of national culture, as a potential explanatory driver for appropriation and rejection and further theorise around our research questions. Equally, we consider that an obvious future step would be a different type of generalisation attempt: rather than generalising to a different population and gauging differences at the basis of cultural values, one could examine whether the theory of trial and error for appropriation is replicable and remains valid for other types of IT devices. This would be of additional interest for the post Covid-19 world, where workers are already moving to working-from-home arrangements, and where the choice of IT artefacts may be made under their own volitional control and at a time when our dependence on technology has been made abundantly clear both for remaining professionally active and socially connected (Seetharaman et al. 2020).

Acknowledgements Prof. Nancy Pouloudi acknowledges the financial support of the Athens University of Economics and Business Research Center.

\section{Appendix 1}


Table 4 Casebook of study

\begin{tabular}{|c|c|c|c|c|c|c|c|c|}
\hline Bn & An & Pseudonym & Country & Gender & Profession & Model & $\begin{array}{l}\text { Publication } \\
\text { date }\end{array}$ & $\begin{array}{l}\text { Access } \\
\text { date }\end{array}$ \\
\hline 1 & 1 & Dale Cooper & China & Male & Marketing \& Business Develop. Executive & iPad 1 & $04 / 05 / 2010$ & $23 / 05 / 2013$ \\
\hline 2 & 2 & Tamara Preston & USA & female & Executive Editor & iPad 2 & $22 / 06 / 2011$ & $24 / 08 / 2012$ \\
\hline 3 & “ & “ & “ & “ & “ & iPad 2 & 02/06/2011 & $23 / 05 / 2013$ \\
\hline 4 & 3 & Albert Rosenfield & USA & Male & journalist & iPad 1 & 2010 & $23 / 05 / 2013$ \\
\hline 5 & 4 & Chester Desmond & Spain & Male & web 2.0 practitioner & iPad Pro & 09/09/2016 & $15 / 06 / 2017$ \\
\hline 6 & “ & “ & “ & “ & “ & iPad 2 & $10 / 05 / 2011$ & $15 / 06 / 2017$ \\
\hline 7 & 5 & Sam Stanley & USA & Male & UX Developer & new iPad & $25 / 03 / 2012$ & $24 / 08 / 2012$ \\
\hline 8 & 6 & Phillip Jeffries & USA & Male & Lead designer & iPad Mini & $23 / 12 / 2012$ & $15 / 06 / 2017$ \\
\hline 9 & & & & & & iPad Mini & $18 / 03 / 2012$ & $15 / 06 / 2017$ \\
\hline 10 & 7 & Roger Hardy & UK & Male & Operations director & new iPad & $23 / 03 / 2012$ & $25 / 08 / 2012$ \\
\hline 11 & 8 & Gordon Cole & USA & Male & Academic & iPad 1 & $21 / 04 / 2010$ & $13 / 05 / 2011$ \\
\hline 12 & 9 & Dennis Bryson & UK & Male & technology writer & iPad Pro & $12 / 11 / 2015$ & $15 / 06 / 2017$ \\
\hline 13 & “" & “ & “ & “ & “ & iPad Pro & $13 / 11 / 2015$ & $15 / 06 / 2017$ \\
\hline 14 & “ & “ & “ & “ & “ & iPad Pro & $16 / 11 / 2015$ & $22 / 06 / 2017$ \\
\hline 15 & “ & “ & “ & “ & “ & iPad Pro & $18 / 11 / 2015$ & $15 / 06 / 2017$ \\
\hline 16 & 10 & Harry S. Truman & USA & Male & technology analyst & iPad Air & $25 / 11 / 2013$ & $22 / 06 / 2017$ \\
\hline 17 & 11 & Andy Brennan & Italy & Male & Editor-in-Chief & $\begin{array}{l}\text { iPad Air } \\
2\end{array}$ & $04 / 02 / 2015$ & $22 / 06 / 2017$ \\
\hline 18 & 12 & Bobby Briggs & USA & Male & Senior Graphic Design Instructor & iPad Pro & $12 / 11 / 2015$ & $22 / 06 / 2017$ \\
\hline 19 & “ & “ & “ & “ & “ & iPad Pro & $23 / 11 / 2015$ & $22 / 06 / 2017$ \\
\hline 20 & 13 & Chad Broxford & USA & Male & Entrepreneur & iPad Mini & $06 / 11 / 2012$ & $22 / 06 / 2017$ \\
\hline 21 & 14 & Jesse Holcomb & USA & Male & Principal Analyst & iPad Pro & $17 / 11 / 2015$ & $22 / 06 / 2017$ \\
\hline 22 & 15 & Cappy & USA & Male & freelance writer & iPad Pro & $23 / 11 / 2015$ & $22 / 06 / 2017$ \\
\hline 23 & 16 & Peter Deming & Australia & Male & Music \& Audio Editor & iPad 2 & $20 / 03 / 2014$ & $22 / 06 / 2017$ \\
\hline 24 & 17 & David Lynch & UK & Male & writer & iPad Pro & $28 / 01 / 2016$ & $22 / 06 / 2017$ \\
\hline 25 & 18 & Sarah Palmer & USA & female & doctor & iPad Mini & $22 / 01 / 2013$ & $22 / 06 / 2017$ \\
\hline 26 & 19 & Richard Horne & USA & Male & business and product development leader & iPad Pro & $30 / 04 / 2016$ & $22 / 06 / 2017$ \\
\hline 27 & 20 & Johnny Horne & USA & Male & $\mathrm{CMO}$ & iPad Pro & $17 / 05 / 2016$ & $22 / 06 / 2017$ \\
\hline 28 & 21 & Andrew Packard & USA & Male & public school district communications & $\begin{array}{l}\text { iPad Air } \\
2\end{array}$ & $26 / 11 / 2014$ & $22 / 06 / 2017$ \\
\hline 29 & 22 & Pete Martell & USA & Male & IT project manager & iPad 2 & 08/05/2011 & $13 / 05 / 2011$ \\
\hline 30 & 23 & Garland Briggs & USA & Male & NA & iPad 1 & $26 / 05 / 2010$ & $13 / 05 / 2011$ \\
\hline 31 & “ & “ & “ & “ & “ & iPad 1 & 09/04/2010 & $13 / 05 / 2011$ \\
\hline 32 & “ & “ & “ & “ & “ & iPad 1 & 09/04/2010 & $13 / 05 / 2011$ \\
\hline 33 & 24 & Steven Burnett & USA & Male & iPhone developer and web developer & iPad 1 & $30 / 05 / 2010$ & $23 / 08 / 2012$ \\
\hline 34 & 25 & Big Ed Hurley & USA & Male & Chief Technology Officer & iPad 1 & 06/05/2010 & $13 / 05 / 2011$ \\
\hline 35 & 26 & James Hurley & USA & Male & filmmaker, photographer, and writer & iPad 2 & $10 / 02 / 2012$ & $22 / 06 / 2017$ \\
\hline 36 & 27 & Hank Jennings & USA & Male & lawyer & iPad 2 & 01/08/2012 & $23 / 08 / 2012$ \\
\hline 37 & 28 & Leo Johnson & UK & Male & UK & iPad Mini & $19 / 11 / 2012$ & $22 / 06 / 2017$ \\
\hline 38 & “ & “ & “ & “ & “ & iPad Pro & $11 / 09 / 2015$ & $15 / 06 / 2017$ \\
\hline 39 & 29 & Jacques Renault & USA & Male & HR professional & iPad 1 & $04 / 05 / 2010$ & $13 / 05 / 2011$ \\
\hline 40 & 30 & Bernard Renault & USA & Male & Venture Partner & iPad 1 & 08/06/2010 & $13 / 05 / 2011$ \\
\hline 41 & 31 & Jean-Michel Renault & USA & Male & Editor in Chief & iPad 1 & 20/09/2010 & $23 / 05 / 2013$ \\
\hline 42 & “ & “ & “ & “ & “ & new iPad & $30 / 03 / 2012$ & $23 / 05 / 2013$ \\
\hline 43 & 32 & Blackie O’Reilly & USA & Male & Software engineer, moderator on Ask Different & new iPad & $27 / 03 / 2012$ & $23 / 05 / 2013$ \\
\hline 44 & “ & “ & “ & “ & “ & new iPad & $28 / 03 / 2012$ & $23 / 05 / 2013$ \\
\hline
\end{tabular}


Table 4 (continued)

\begin{tabular}{|c|c|c|c|c|c|c|c|c|}
\hline Bn & An & Pseudonym & Country & Gender & Profession & Model & $\begin{array}{l}\text { Publication } \\
\text { date }\end{array}$ & $\begin{array}{l}\text { Access } \\
\text { date }\end{array}$ \\
\hline 45 & 33 & Lawrence Jacoby & Netherlands & Male & Chief Executive Officer & iPad 1 & $24 / 08 / 2010$ & $13 / 05 / 2011$ \\
\hline 46 & 34 & Mike Nelson & USA & Male & Musician & iPad 1 & $06 / 10 / 2010$ & $25 / 09 / 2012$ \\
\hline 47 & “ & “ & “ & “ & “ & iPad 1 & $06 / 10 / 2010$ & $25 / 09 / 2012$ \\
\hline 48 & “ & “ & “ & “ & “ & iPad 1 & $19 / 07 / 2010$ & $25 / 09 / 2012$ \\
\hline 49 & 35 & Maddy Ferguson & USA & female & Academic & iPad 2 & $25 / 03 / 2011$ & $23 / 08 / 2012$ \\
\hline 50 & 36 & Harold Smith & Netherlands & Male & UX consultant & iPad 1 & $10 / 01 / 2010$ & $13 / 05 / 2011$ \\
\hline 51 & 37 & Donna Hayward & USA & female & Writer & iPad Mini & $02 / 04 / 2015$ & $15 / 06 / 2017$ \\
\hline 52 & 38 & Emory Battis & Finland & Male & Senior UX and concept designer and consultant & iPad 1 & $13 / 08 / 2010$ & $13 / 05 / 2011$ \\
\hline 53 & 39 & Tommy Hill & UK & male & & iPad 1 & $22 / 08 / 2012$ & $24 / 08 / 2012$ \\
\hline 54 & 40 & Dwayne Milford & Albania & Male & IT specialist & iPad 1 & $14 / 02 / 2011$ & $13 / 05 / 2011$ \\
\hline 55 & 41 & Harriet Hayward & USA & female & litigator & iPad Pro & $21 / 03 / 2016$ & $15 / 06 / 2017$ \\
\hline 56 & “ & “ & “ & “ & “ & new iPad & $27 / 03 / 2012$ & $23 / 06 / 2017$ \\
\hline 57 & 42 & Dougie Milford & USA & Male & Editor in Chief & new iPad & $23 / 03 / 2012$ & $25 / 08 / 2012$ \\
\hline 58 & “ & “ & “ & “ & “ & iPad 2 & $16 / 03 / 2011$ & $25 / 08 / 2012$ \\
\hline 59 & 43 & Carl Rodd & UK & Male & Chartered accountant & iPad 1 & $06 / 05 / 2010$ & $13 / 05 / 2011$ \\
\hline 60 & “ & “ & “ & “ & “ & iPad 1 & $12 / 06 / 2010$ & $13 / 05 / 2011$ \\
\hline 61 & “ & “ & “ & “ & “ & iPad 1 & 01/02/2010 & $13 / 05 / 2011$ \\
\hline 62 & 44 & Malcolm Sloan & USA & Male & Science fiction writer & iPad 2 & $30 / 05 / 2011$ & $24 / 08 / 2012$ \\
\hline 63 & “ & “ & “ & “ & “ & iPad 2 & $31 / 05 / 2011$ & $24 / 08 / 2012$ \\
\hline 64 & “ & “ & “ & “ & “ & iPad 2 & 01/06/2011 & $24 / 08 / 2012$ \\
\hline 65 & “ & “ & “ & “ & “ & iPad 2 & $02 / 06 / 2011$ & $24 / 08 / 2012$ \\
\hline 66 & “ & “ & “ & “ & “ & iPad 2 & 03/06/2011 & $24 / 08 / 2012$ \\
\hline 67 & “ & “ & “ & “ & “ & iPad 2 & $26 / 05 / 2012$ & $24 / 08 / 2012$ \\
\hline 68 & “ & “ & “ & “ & “ & iPad 2 & $28 / 01 / 2017$ & $23 / 06 / 2017$ \\
\hline 69 & “ & “ & “ & “ & “ & iPad 2 & 04/01/2012 & $23 / 06 / 2017$ \\
\hline 70 & “ & “ & “ & “ & “ & iPad 2 & 04/08/2011 & $23 / 06 / 2017$ \\
\hline 71 & “ & “ & “ & “ & “ & iPad 2 & 04/07/2011 & $23 / 06 / 2017$ \\
\hline 72 & “ & “ & “ & “ & “ & iPad 2 & $24 / 05 / 2011$ & $24 / 08 / 2012$ \\
\hline 73 & “ & “ & “ & “ & “ & iPad 2 & $11 / 05 / 2011$ & $24 / 08 / 2012$ \\
\hline 74 & “ & “ & “ & “ & “ & iPad 2 & $28 / 01 / 2010$ & $24 / 08 / 2012$ \\
\hline 75 & “ & “ & “ & “ & “ & iPad 2 & $31 / 01 / 2011$ & $24 / 08 / 2012$ \\
\hline 76 & “ & “ & “ & “ & “ & iPad 2 & $25 / 05 / 2011$ & $24 / 08 / 2012$ \\
\hline 77 & 45 & Thomas Eckhardt & UK & Male & Technology architect & iPad 1 & $10 / 10 / 2010$ & $13 / 05 / 2011$ \\
\hline 78 & 46 & Windom Earle & UK & Male & Executive Editor & iPad 1 & $23 / 04 / 2010$ & $13 / 05 / 2011$ \\
\hline 79 & “ & “ & “ & “ & “ & iPad 2 & $04 / 04 / 2011$ & $13 / 05 / 2011$ \\
\hline 80 & 47 & John Justice Wheeler & USA & Male & Academic & iPad 1 & $17 / 06 / 2010$ & $13 / 05 / 2011$ \\
\hline 81 & 48 & Gersten Hayward & USA & female & Internet Marketer & iPad 1 & $11 / 05 / 2010$ & $13 / 05 / 2011$ \\
\hline 82 & 49 & Mike & Canada & Male & Chief Technology Officer & iPad 2 & $26 / 03 / 2011$ & $13 / 05 / 2011$ \\
\hline 83 & 50 & Bob & USA & Male & twitter designer & iPad 2 & $20 / 03 / 2011$ & $13 / 05 / 2011$ \\
\hline 84 & 51 & Pierre Tremond/ & UK & Male & digital marketing & new iPad & NA & $24 / 08 / 2012$ \\
\hline 85 & “ & “ & “ & “ & “ & iPad 2 & NA & $24 / 08 / 2012$ \\
\hline 86 & 52 & Douglas Jones & Canada & Male & freelance web designer, developer & iPad 1 & 04/10/2010 & $15 / 06 / 2017$ \\
\hline 87 & 53 & Sonny Jim Jones & USA & Male & analyst & iPad 1 & 05/06/2010 & $23 / 06 / 2017$ \\
\hline 88 & 54 & Bradley Mitchum & USA & Male & strategic communications manager & iPad 2 & $12 / 07 / 2012$ & $13 / 05 / 2011$ \\
\hline 89 & 55 & Rodney Mitchum & USA & Male & attorney & iPad Air & $04 / 11 / 2013$ & $24 / 06 / 2017$ \\
\hline 90 & 56 & Duncan Todd & USA & Male & Principal Analyst \& Co-founder & iPad Pro & $12 / 05 / 2017$ & $24 / 06 / 2017$ \\
\hline 91 & 57 & Ike Stadtler & USA & Male & musician & iPad 2 & $22 / 06 / 2013$ & $24 / 06 / 2017$ \\
\hline 92 & 58 & Sam Colby & USA & Male & technology writer/blogger & iPad 1 & $04 / 04 / 2010$ & $24 / 06 / 2017$ \\
\hline
\end{tabular}


Table 4 (continued)

\begin{tabular}{|c|c|c|c|c|c|c|c|c|}
\hline Bn & An & Pseudonym & Country & Gender & Profession & Model & $\begin{array}{l}\text { Publication } \\
\text { date }\end{array}$ & $\begin{array}{l}\text { Access } \\
\text { date }\end{array}$ \\
\hline 93 & 59 & Don Harrison & USA & Male & FAA Designated Pilot Examiner & ipad air 2 & $10 / 11 / 2014$ & $24 / 06 / 2017$ \\
\hline 94 & 60 & Dave Macklay & canada & Male & Full Stack Engineer & iPad Pro & $06 / 05 / 2016$ & $15 / 06 / 2017$ \\
\hline 95 & 61 & Mike Boyd & USA & Male & $\begin{array}{l}\text { Business Development and Marketing } \\
\text { Coordinator }\end{array}$ & iPad 2 & $27 / 04 / 2011$ & $15 / 06 / 2017$ \\
\hline 96 & 62 & Sylvia Horne & Canada & female & Ghost writer, consultant & iPad 1 & $15 / 05 / 2010$ & $24 / 08 / 2012$ \\
\hline 97 & 63 & Frank Silva & USA & Male & $\mathrm{PhD}$ candidate & iPad 2 & $06 / 04 / 2011$ & $13 / 05 / 2011$ \\
\hline 98 & 64 & $\begin{array}{l}\text { Phillip Michael } \\
\text { Gerard }\end{array}$ & USA & Male & NA & iPad 2 & $06 / 04 / 2011$ & $24 / 06 / 2017$ \\
\hline 99 & 65 & Michael J. Anderson & USA & Male & MD-PhD student & $\mathrm{iPad} 2$ & $23 / 10 / 2011$ & $24 / 06 / 2017$ \\
\hline 100 & 66 & Ronnie Rocket & USA & Male & Pastor & iPad 1 & $10 / 06 / 2010$ & $25 / 08 / 2012$ \\
\hline 101 & “ & “ & “ & “ & “ & iPad 1 & NA & $25 / 08 / 2012$ \\
\hline 102 & “ & “ & “ & “ & “ & iPad 1 & $12 / 05 / 2010$ & $25 / 08 / 2012$ \\
\hline 103 & “ & “ & “ & “ & “ & iPad Mini & $19 / 03 / 2013$ & $28 / 06 / 2017$ \\
\hline 104 & “ & “ & “ & “ & “ & iPad 1 & $22 / 06 / 2011$ & $28 / 06 / 2017$ \\
\hline 105 & “ & “ & “ & “ & “ & iPad Pro & 08/09/2016 & $28 / 06 / 2017$ \\
\hline 106 & 67 & Audrey Horne & Australia & Female & Digital strategist & iPad 1 & $30 / 07 / 2010$ & $13 / 05 / 2011$ \\
\hline 107 & 68 & Miguel Ferrer & USA & Male & Editor & iPad 2 & $05 / 12 / 2011$ & $25 / 08 / 2012$ \\
\hline 108 & 69 & Michael Ontkean & USA & Male & surgeon & iPad 2 & $09 / 05 / 2011$ & $15 / 06 / 2017$ \\
\hline 109 & 70 & Josie Packard & USA & Female & Freelance journalist and blogger & iPad 1 & $22 / 07 / 2010$ & $23 / 05 / 2013$ \\
\hline 110 & “ & “ & “ & “ & “ & iPad 1 & $15 / 09 / 2010$ & $23 / 05 / 2013$ \\
\hline 111 & 71 & Harry Goaz & UK & Male & independent consultant & iPad 2 & $10 / 04 / 2012$ & $25 / 08 / 2012$ \\
\hline 112 & 72 & James Stewart & USA & Male & technology entrepreneur & iPad 1 & $23 / 04 / 2010$ & $25 / 08 / 2012$ \\
\hline 113 & 73 & Warren Frost & USA & Male & user experience professional & iPad 1 & $25 / 07 / 2010$ & $23 / 08 / 2012$ \\
\hline 114 & 74 & Benjamin Horne & USA & Male & Senior Software Engineer & iPad 1 & $12 / 04 / 2010$ & $25 / 08 / 2012$ \\
\hline 115 & 75 & Catherine Martell & USA & Female & fashion blogger & iPad 2 & $20 / 03 / 2011$ & $23 / 05 / 2013$ \\
\hline 116 & 76 & Everett McGill & USA & Male & Naval architect & iPad 2 & $18 / 03 / 2011$ & $23 / 05 / 2013$ \\
\hline 117 & 77 & Walter Olkewicz & UK & Male & $\begin{array}{l}\text { user experience designer and information } \\
\text { architect }\end{array}$ & iPad 1 & $08 / 04 / 2010$ & $13 / 05 / 2011$ \\
\hline 118 & 78 & Janek Pulaski & USA & Male & Minister & iPad 1 & $16 / 10 / 2010$ & $13 / 05 / 2011$ \\
\hline 119 & 79 & Russ Tamblyn & UK & Male & Independent Design Professional & new iPad & $09 / 04 / 2012$ & $23 / 05 / 2013$ \\
\hline 120 & 80 & Gary Hershberger & USA & Male & technology analyst & $\begin{array}{l}\text { iPad Air } \\
\quad 2\end{array}$ & $08 / 06 / 2015$ & $15 / 06 / 2017$ \\
\hline 121 & 81 & David Warner & USA & Male & Photographer & iPad Pro & $16 / 04 / 2017$ & $15 / 06 / 2017$ \\
\hline 122 & 82 & Mark Frost & USA & Male & Chief operations officer & iPad 1 & $04 / 04 / 2010$ & $13 / 05 / 2011$ \\
\hline 123 & 83 & Robert Engels & USA & Male & IT professional & new iPad & $01 / 07 / 2012$ & $25 / 08 / 2012$ \\
\hline 124 & 84 & Angelo Badalamenti & USA & Male & Academic & $\mathrm{iPad} 2$ & NA & $24 / 08 / 2012$ \\
\hline 125 & “ & “ & “ & “ & “ & $\mathrm{iPad} 2$ & $27 / 11 / 2012$ & $03 / 07 / 2017$ \\
\hline 126 & “ & “ & “ & “ & “ & iPad 2 & $03 / 11 / 2010$ & $03 / 07 / 2017$ \\
\hline 127 & 85 & Andrew Packard & UK & Male & writer & iPad Pro & $27 / 06 / 2017$ & $03 / 07 / 2017$ \\
\hline 128 & “ & “ & “ & “ & “ & iPad Pro & $12 / 06 / 2017$ & $03 / 07 / 2017$ \\
\hline 129 & “ & “ & “ & “ & “ & iPad Pro & $23 / 02 / 2017$ & $03 / 07 / 2017$ \\
\hline 130 & “ & “ & “ & “ & “ & iPad Pro & $27 / 01 / 2017$ & 03/07/2017 \\
\hline 131 & “ & “ & “ & “ & “ & iPad Pro & $26 / 11 / 2016$ & $03 / 07 / 2017$ \\
\hline 132 & “ & “ & “ & “ & “ & iPad Pro & $13 / 11 / 2016$ & 03/07/2017 \\
\hline 133 & “ & “ & “ & “ & “ & iPad Pro & $12 / 11 / 2016$ & 03/07/2017 \\
\hline 134 & “ & “ & “ & “ & “ & iPad Pro & $09 / 11 / 2016$ & $03 / 07 / 2017$ \\
\hline 135 & “ & “ & “ & “ & “ & iPad Pro & $08 / 11 / 2016$ & 03/07/2017 \\
\hline 136 & “ & “ & “ & “ & “ & iPad Pro & $01 / 11 / 2016$ & 03/07/2017 \\
\hline
\end{tabular}




\section{Appendix 2}

We collected the empirical material in two stages, between March 2011-August 2012, and January 2017-July 2017

During the first stage, we collected 49 blogposts, authored by 37 unique bloggers. During the second stage, we collected in addition 87 blogposts, authored by 48 unique bloggers. The complete casebook of the study is shown in Table 4 (Appendix 1).

For both stages, our search strategy entailed initiating a Google search at first, using the following keywords: "experience" AND "iPad" AND "blog".

We initially conducted this research in a nondiscriminatory manner, in order to get a preliminary idea about the themes bloggers tend to discuss. We then focused specifically on the main blogging platforms, i.e., WordPress. com, medium.com, blogger.com, tumblr.com, posterous.com (now defunct). Within these platforms, we used the search functionality as well as the hashtag or the tag functionality to identify additional relevant posts (snowball sampling).

The collated blog posts were then examined against our inclusion and exclusion criteria. We excluded any blogpost that could be seen as being a technical review, as affiliated directly or indirectly with Apple Inc. or as containing indications that the blogpost has been endorsed in some way or sponsored by any of the manufacturers/developers of any of the products and/or services mentioned in the blog.

Relatedly, to be included, each blogpost had to: a) contain a rich description of the blogger's interaction with the tablet, $b$ ) describe voluntary use of the device within both professional and personal use scenarios, c) contain a description of negative disconfirmation i.e., the user attempts to use the device in a particular way but failing to do so for one or more reasons, and d) describe an underlying effort to overcome disconfirmation. These criteria allowed us to collect material that contained contextual and processual information, supporting us in addressing our research question.

Specifically for the second stage of data collection (January 2017-July 2017), which was driven by theoretical sampling, we purposefully sampled blogposts with the aim to enrich the meaning of our existing emerging codes, rather than expand the reach of our evolving theory. In other words, we aimed at identifying additional cases, where blog authors were discussing the same concepts, so that we could densify our theory, by verifying the usefulness of the core categories and establishing the core conditions for each.

Considering the nature of our empirical material, it is critical to note that some of the blogging platforms are now defunct, and several of the blogs are not online anymore. For example, posterous.com, once a very popular blogging platform, shut down in early 2013 (Bishop 2013). With it, lots of our empirical material vanished. Similarly, when in late 2018, tumblr.com announced the ban of a certain type of content, millions of posts vanished from the platform, which led to a mass migration of users onto other platforms (Stephen 2018). This has meant that, again, a lot of our empirical material disappeared from the online world. However, we do have a full record of all the blogposts that we have used for our analysis, as we have kept a detailed offline record for each, which have imported into Nvivo for analysis purposes, and the entire casebook can be made available by the first author upon request.

\section{References}

Aggarwal, R., Kryscynski, D., Midha, V., Singh, H. (2015). Early to adopt and early to discontinue: The impact of self-perceived and actual IT knowledge on technology use behaviors of end users. Information Systems Research 26 (1), 127-144. https://doi.org/10. 1287/isre.2014.0564.

Ahuja, M. K., \& Thatcher, J. B. (2005). Moving beyond intentions and toward the theory of trying: Effects of work environment and gender on post-adoption information technology use. MIS Quarterly: Management Information Systems, 29(3), 427-459.

Alblas, A. A., \& Langerak, F. (2015). The impact of design debugging on new product development speed: The significance of improvisational and trial-and-error learning. POMS 26th Annual ConferenceProduction and Operations Management Society (POMS). POMS 26th Annual Conference - Production and Operations Management Society (POMS), Washington D.C., USA.

Alter, S. (2014). Theory of workarounds. Communications of the Association for Information Systems, 34, 1041-1066.

Azad, B., \& King, N. (2008). Enacting computer workaround practices within a medication dispensing system. European Journal of Information Systems, 17(3), 264-278.

Azad, B., \& King, N. (2011). Institutionalized computer workaround practices in a Mediterranean country: An examination of two organizations. European Journal of Information Systems, 21(4), 358372.

Bagayogo, F. F., Lapointe, L., \& Bassellier, G. (2014). Enhanced use of IT: A new perspective on post-adoption. Journal of the Association of Information Systems, 15(7), 361-387.

Barki, H., Titah, R., \& Boffo, C. (2007). Information system use-related activity: An expanded Behavioral conceptualization of individuallevel information system use. Information Systems Research, 18(2), 173-192. https://doi.org/10.1287/isre.1070.0122.

Barnett, T., Pearson, A. W., Pearson, R., \& Kellermanns, F. W. (2015). Five-factor model personality traits as predictors of perceived and actual usage of technology. European Journal of Information Systems, 24(4), 374-390. https://doi.org/10.1057/ejis.2014.10.

Barrett, A. K. (2018). Technological appropriations as workarounds: Integrating electronic health records and adaptive structuration theory research. Information Technology \& People, 31(2), 368-387. https://doi.org/10.1108/ITP-01-2016-0023.

Barrett, M., \& Walsham, G. (1999). Electronic trading and work transformation in the London insurance market. Information Systems Research, 10(1), 1-22.

Beaudry, A., \& Pinsonneault, A. (1998). Appropriation of information technology: A requisite for improved individual performance. Americas Conference on Information Systems (AMCIS 1998). http://aisel.aisnet.org/amcis1998/238

Beaudry, A., \& Pinsonneault, A. (2005). Understanding user responses to information technology: A coping model of user adaptation. MIS Quarterly, 29(3), 493-524. 
Bhattacherjee, A., \& Premkumar, G. (2004). Understanding changes in belief and attitude toward information technology usage: A theoretical model and longitudinal test. MIS Quarterly, 28(2), 229-254. https://doi.org/10.2307/25148634.

Bhattacherjee, A. (2001). Understhanding information systems continuance: An expectation confirmation model. MIS Quarterly, 25(3), 351-370.

Bishop, B. (2013). Blogging platform Posterous to shut down on April 30th. The Verge. https://www.theverge.com/2013/2/15/3993770/ blogging-platform-posterous-to-shut-down-on-april-30th

Boudreau, M.-C., \& Robey, D. (2005). Enacting integrated information technology: A human agency perspective. Organization Science, 16(1), 3-18.

Brohman, K., Addas, S., Dixon, J., \& Pinsonneault, A. (2020). Cascading feedback: A longitudinal study of a feedback ecosystem for Telemonitoring patients with chronic disease. MIS Quarterly, 44(1), 421-450. https://doi.org/10.25300/MISQ/2020/15089.

Burton-Jones, A., \& Straub, D. W. (2006). Reconceptualizing system usage: An approach and empirical test. Information Systems Research, 17(3), 228-246. https://doi.org/10.1287/isre.1060.0096.

Carroll, J., \& Fidock, J. (2011). Beyond resistance to technology appropriation. 44th Hawaii international conference on system sciences (HICSS 44), 1-9. https://doi.org/10.1109/HICSS.2011.82.

Charmaz, K. (2006). Constructing grounded theory. A Practical Guide through Qualitative Analysis. SAGE Publications.

Chatterjee, S., Moody, G., Lowry, P. B., Chakraborty, S., \& Hardin, A. (2015). Strategic relevance of organizational virtues enabled by information Technology in Organizational Innovation. Journal of Management Information Systems, 32(3), 158-196. https://doi.org/ 10.1080/07421222.2015.1099180.

Choudrie, J., Zamani, E. D., Krepel, B., \& Stewart, M. A. (2016). Understanding individual user resistance and workarounds of Enterprise social networks: The case of service ltd. Journal of Information Technology, 31(2), 130-151. https://doi.org/10.1057/ jit.2016.9.

Chu, X., Luo, X. R., \& Chen, Y. (2019). A systematic review on crosscultural information systems research: Evidence from the last decade. Information \& Management, 56(3), 403-417. https://doi.org/ 10.1016/j.im.2018.08.001.

Ciborra, C. (1999). Notes on improvisation and time in organizations. Accounting, Management and Information Technologies, 9(2), 77-94. https://doi.org/10.1016/S0959-8022(99)00002-8.

Ciborra, C. (2002). The labyrinths of information: Challenging the wisdom of systems. Oxford University Press.

Clark, P. A. (1987). Anglo-American innovation. Walter de Gruyter GmbH \& Co KG.

Costall, A. (1993). How Lloyd Morgan's canon backfired. Journal of the History of the Behavioral Sciences, 29(2), 113-122. https://doi.org/ 10.1002/1520-6696(199304)29:2<113::AID-JHBS2300290203>3. $0 . \mathrm{CO} ; 2-\mathrm{G}$.

Cram, W. A., \& Marabelli, M. (2018). Have your cake and eat it too? Simultaneously pursuing the knowledge-sharing benefits of agile and traditional development approaches. Information \& Management, 55(3), 322-339. https://doi.org/10.1016/j.im.2017. 08.005 .

Dang, Y. M., Zhang, Y. G., Brown, S. A., \& Chen, H. (2020). Examining the impacts of mental workload and task-technology fit on user acceptance of the social media search system. Information Systems Frontiers, 22(3), 697-718. https://doi.org/10.1007/s10796-0189879-y.

Dang-Pham, D., Pittayachawan, S., Bruno, V., \& Kautz, K. (2019). Investigating the diffusion of IT consumerization in the workplace: A case study using social network analysis. Information Systems Frontiers, 21(4), 941-955. https://doi.org/10.1007/s10796-0179796-5.
Davis, F. D., Bagozzi, R. . P., \& Warshaw, P. R. (1989). User acceptance of computer technology: A comparison of two theoretical models. Management Science, 35(8), 982-1003.

Davison, R. M., \& Martinsons, M. G. (2016). Context is king! Considering particularism in research design and reporting. Journal of Information Technology, 31(3), 241-249. https://doi. org/10.1057/jit.2015.19.

Dennis, A. R., Wixom, B. H., \& Vandenberg, R. J. (2001). Understanding Fit and Appropriation Effects in Group Support Systems via Meta-Analysis., 25(2), 167-193.

DeSanctis, G., \& Poole, M. S. (1994). Capturing the complexity in advanced technology use: Adaptive structuration theory. Organization Science, 5, 121-147.

Doargajudhur, M. S., \& Dell, P. (2019). Impact of BYOD on organizational commitment: An empirical investigation. Information Technology \& People, 32(2), 246-268. https://doi.org/10.1108/ ITP-11-2017-0378.

Elbanna, A. (2006). The validity of the improvisation argument in the implementation of rigid technology: The case of ERP systems. Journal of Information Technology, 21(3), 165-175.

Elbanna, A., \& Linderoth, H. C. J. (2015). The formation of technology mental models: The case of voluntary use of technology in organizational setting. Information Systems Frontiers, 17(1), 95-108. https://doi.org/10.1007/s10796-014-9513-6.

Elie-Dit-Cosaque, C., \& Pallud, J. (2010). User Adaptation and IS Success: An Empirical Investigation among French Workers. International conference of information systems (ICIS 2010). http://aisel.aisnet.org/icis2010 submissions/158

Fernandes, K. J. (2005). Eureka moments in the works of Claudio Ciborra. European Journal of Information Systems, 14(5), 498499. https://doi.org/10.1057/palgrave.ejis.3000556.

Ferneley, E. H., \& Sobreperez, P. (2006). Resist, comply or workaround? An examination of different facets of user engagement with information systems. European Journal of Information Systems, 15(4), $345-356$.

George, J. F., Gupta, M., Giordano, G., Mills, A. M., Tennant, V. M., \& Lewis, C. C. (2018). The effects of communication media and culture on deception detection accuracy. MIS Quarterly, 42(2), 551575. https://doi.org/10.25300/MISQ/2018/13215.

Glaser, B. G. (1978). Theoretical sensitivity: Advances in the methodology of grounded theory. The Sociology Press.

Glaser, B. G., \& Strauss, A. (1967). The discovery of grounded theory: Strategies for qualitative research. Aldine Publishing Co.

Gupta, M., Esmaeilzadeh, P., Uz, I., \& Tennant, V. M. (2019a). The effects of national cultural values on individuals' intention to participate in peer-to-peer sharing economy. Journal of Business Research, 97, 20-29. https://doi.org/10.1016/j.jbusres.2018.12.018.

Gupta, M., George, J. F., \& Xia, W. (2019b). Relationships between IT department culture and agile software development practices: An empirical investigation. International Journal of Information Management, 44, 13-24. https://doi.org/10.1016/j.ijinfomgt.2018. 09.006 .

Haug, M., Gewald, H., \& Rockmann, R. (2018). Grandma's new tablet The role of Mobile devices in trying to innovate in IT. Procedia Computer Science, 141, 460-465. https://doi.org/10.1016/j.procs. 2018.10.142

Hekkala, R., \& Urquhart, C. (2013). Everyday power struggles: Living in an IOIS project. European Journal of Information Systems, 22(1), 76-94. https://doi.org/10.1057/ejis.2012.43.

Hennink, M. M., Kaiser, B. N., \& Marconi, V. C. (2017). Code saturation versus meaning saturation: How many interviews are enough? Qualitative Health Research, 27(4), 591-608. https://doi.org/10. 1177/1049732316665344.

Hookway, N. S. (2008). Human Documents Research: From the Diary to the Blog. 1-18. 
Hovav, A., \& Putri, F. F. (2016). This is my device! Why should I follow your rules? Employees' compliance with BYOD security policy. Pervasive and Mobile Computing, 32, 35-49. https://doi.org/10. 1016/j.pmcj.2016.06.007.

Jasperson, J., Carter, P. E., \& Zmud, R. W. (2005). A comprehensive conceptualization of post-adoptive Behaviors associated with information technology enabled work systems. MIS Quarterly, 29(3), 525-557. https://doi.org/10.2307/25148694.

Kendall, L., Chaudhuri, B., \& Bhalla, A. (2020). Understanding technology as situated practice: Everyday use of voice user interfaces among diverse groups of users in urban India. Information Systems Frontiers, 22(3), 585-605. https://doi.org/10.1007/s10796-02010015-6.

Kim, S., \& Garrison, G. (2009). Investigating mobile wireless technology adoption: An extension of the technology acceptance model. Information Systems Frontiers, 11(3), 323-333.

Koopman, P., \& Hoffman, R. R. (2003). Work-arounds, make-work, and kludges. IEEE Intelligent Systems, 18(6), 70-75.

Korica, M., \& Molloy, E. (2010). Making sense of professional identities: Stories of medical professionals and new technologies. Human Relations, 63(12), 1879-1901. https://doi.org/10.1177/ 0018726710367441 .

Kwahk, K.-Y., Ahn, H., \& Ryu, Y. U. (2018). Understanding mandatory IS use behavior: How outcome expectations affect conative IS use. International Journal of Information Management, 38(1), 64-76. https://doi.org/10.1016/j.ijinfomgt.2017.07.001.

Lapointe, L., \& Beaudry, A. (2014). Identifying IT user Mindsets: Acceptance. Resistance and Ambivalence., 4619-4628. https://doi. org/10.1109/HICSS.2014.568.

Lee, J. Y.-H., Panteli, N., Bülow, A. M., \& Hsu, C. (2018). Email adaptation for conflict handling: A case study of cross-border interorganisational partnership in East Asia. Information Systems Journal, 28(2), 318-339. https://doi.org/10.1111/isj.12139.

Leonardi, P. M., \& Barley, S. R. (2010). What's under construction Here? Social action, materiality, and power in constructivist studies of technology and organizing. The Academy of Management Annals, 4, 1-51.

Lin, Y.-K., Lin, M., \& Chen, H. (2019). Do electronic health records affect quality of care? Evidence from the HITECH act. Information Systems Research, 30(1), 306-318. https://doi.org/10. 1287/isre.2018.0813.

Magni, M., Maruping, L., Caporarello, L., \& Basaglia, S. (2011). Innovating with technology in team contexts: A trait activation theory perspective. International conference on information systems (ICIS 2011), Shanghai.

Mäkelä, S., \& Vellonen, V. (2018). Designing for appropriation: A DIY kit as an educator's tool in special education schools. International Journal of Human-Computer Studies, 118, 14-23. https://doi.org/ 10.1016/j.ijhcs.2018.05.004

McGann, S., \& Lyytinen, K. (2008, January 1). The Improvisation Effect: A Case Study of User Improvisation and Its Effects on Information System Evolution. International Conference of Information Systems. http://aisel.aisnet.org/icis2008/209

Miles, M. B., \& Huberman, A. M. (1994). Qualitative data analysis (2nd ed.). Sage Publications.

Miner, A. S., Bassoff, P., \& Moorman, C. (2001). Organizational improvisation and learning: A field study. Administrative Science Quarterly, 46(2), 304. https://doi.org/10.2307/2667089.

Molnar, W. A., Nandhakumar, J., \& Stacey, P. (2017). A paradox of progressive saturation: The changing nature of improvisation over time in a systems development project. Journal of the Association for Information Systems, 18(11), 814-836.

Morrison, B. (2015). The problem with workarounds is that they work: The persistence of resource shortages. Journal of Operations Management, 39-40, 79-91. https://doi.org/10.1016/j.jom.2015. 07.008
Orlikowski, W. (1996). Improvising organizational transformation over time: A situated change perspective. Information Systems Research, 7(1), 63-92.

Orlikowski, W., \& Gash, D. C. (1994). Technological frames: Making sense of information technology in organizations. ACM Transactions on Information Systems, 12(2), 174-207.

Pallud, J., \& Elie-dit-Cosaque, C. (2011). User responses to new system implementation: A Bricolage perspective. International Conference Information Systems (ICIS 2011). http://aisel.aisnet.org/icis2011/ proceedings/humanbehavior/19

Pavlou, P. A., \& El Sawy, O. A. (2010). The "third hand": IT-enabled competitive advantage in turbulence through improvisational capabilities. Information Systems Research, 21(3), 443-471. https://doi. org/10.1287/isre.1100.0280.

Repenning, N. P. (2001). Understanding fire fighting in new product development. Journal of Product Innovation Management, 18(5), 285-300. https://doi.org/10.1111/1540-5885.1850285.

Rerup, C., \& Feldman, M. S. (2011). Routines as A source of change in organizational schemata: The role of trial-and-error learning. The Academy of Management Journal, 54(3), 577-610.

Richter, A., \& Riemer, K. (2009). Corporate Social Networking SitesModes of Use and Appropriation through Co-Evolution. 20th Australasian Conference on Information Systems ACIS 2009. 20th Australasian conference on information systems ACIS 2009, Melbourne, Australia.

Riemer, K., \& Johnston, R. B. (2013). What is IT in use and why does it matter for IS design? Systems. Signs \& Actions, 7(1), 5-21.

Riemer, K., Overfeld, P., Scifleet, P., \& Richter, A. (2012). Eliciting the anatomy of technology appropriation processes: A case study in Enterprise social media. European Conference of Information Systems (ECIS 2012). Europ. Conf. Information systems (ECIS 2012). http://works.bepress.com/alexander richter/1

Roetzel, P., \& Fehrenbacher, D. (2019). On the role of information overload in information systems (IS) success: Empirical evidence from decision support systems. International conference of information systems (ICIS2019), Munich, Germany. https://aisel.aisnet.org/ icis2019/general_topics/general_topics/21

Rossi, M., Nandhakumar, J., \& Mattila, M. (2020). Balancing fluid and cemented routines in a digital workplace. The Journal of Strategic Information Systems, 29(2), 101616. https://doi.org/10.1016/j.jsis. 2020.101616.

Scheibe, K. P., \& Gupta, M. (2017). The effect of socialization via computer-mediated communication on the relationship between organizational culture and organizational creativity. Communications of the Association for Information Systems, 40, 294-314. https://doi. org/10.17705/1CAIS.04013.

Scheiner, C. W., Baccarella, C. V., Feller, N., Voigt, K.-I., \& Bessant, J. (2016). Organisational and individual unlearning in identification and evaluation of technologies. International Journal of Innovation Management, 20(02), 1650017. https://doi.org/10. $1142 / \mathrm{S} 1363919616500171$

Schmitz, K. W., Teng, J. T. C., \& Webb, K. J. (2016). Capturing the complexity of malleable IT use: Adaptive structuration theory for individuals. MIS Quarterly, 40(3), 663-686. https://doi.org/10. 25300/MISQ/2016/40.3.07

Seetharaman, P., Mathew, S. K., Sein, M. K., \& Tallamraju, R. B. (2020). Being (more) human in a digitized world. Information Systems Frontiers, 22(3), 529-532. https://doi.org/10.1007/s10796-02010020-9.

Shirahada, K., \& Hamazaki, K. (2013). Trial and error mindset of R\&D personnel and its relationship to organizational creative climate. Technological Forecasting and Social Change, 80(6), 1108-1118. https://doi.org/10.1016/j.techfore.2012.09.005.

Stephen, B. (2018). Tumblr's porn ban could be its downfall—After all, it happened to LiveJournal. The Verge. https://www.theverge.com/ 2018/12/6/18127869/tumblr-livejournal-porn-ban-strikethrough 
Sun, H. (2012). Understanding user revisions when using information system features: Adaptive system use and triggers. MIS Quarterly, $36(2), 453-478$.

Swan, J., Bresnen, M., Newell, S., \& Robertson, M. (2007). The object of knowledge: The role of objects in biomedical innovation. Human Relations, 60(12), 1809-1837. https://doi.org/10.1177/ 0018726707084915 .

Swann, J. (1999). What happens when learning takes place? Interchange, 30(3), 257-282. https://doi.org/10.1023/A:1007652708139.

Tams, S., Thatcher, J. B., \& Craig, K. (2018). How and why trust matters in post-adoptive usage: The mediating roles of internal and external self-efficacy. The Journal of Strategic Information Systems, 27(2), 170-190. https://doi.org/10.1016/j.jsis.2017.07.004.

Urquhart, C. (2012). Grounded theory for qualitative research. A Practical Guide: SAGE Publications Ltd.

Urquhart, C., \& Fernández, W. (2013). Using grounded theory method in information systems: The researcher as blank slate and other myths. Journal of Information Technology, 28(3), 224-236. https://doi.org/ 10.1057/jit.2012.34.

Vaast, E., \& Levina, N. (2006). Multiple faces of codification: Organizational redesign in an IT organization. Organization Science, 17(2), 190-201. https://doi.org/10.1287/orsc.1050.0171.

Venkatesh, V., \& Davis, F. D. (2000). A theoretical extension of the technology acceptance model: Four longitudinal field studies. Management Science, 46(2), 186-205.

Venkatesh, V., Morris, M. G., Davis, G. B., \& Davis, F. D. (2003). User acceptance of information technology: Towards a unified view. MIS Quarterly, 27(3), 425-478.

Venkatesh, V., Thong, J. Y. L., Chan, F. K. Y., Hu, P. J.-H., \& Brown, S. A. (2011). Extending the two-stage information systems continuance model: Incorporating UTAUT predictors and the role of context. Information Systems Journal, 21(6), 527-555.

Volkoff, O., Strong, D. M., \& Elmes, M. B. (2007). Technological Embeddedness and organizational change. Organization Science, 18(5), 832-848. https://doi.org/10.1287/orsc.1070.0288.

Wiesche, M., Jurisch, M. C., Yetton, P. W., \& Krcmar, H. (2017). Grounded theory methodology in information systems research. MIS Quarterly, 41(3), 685-701.

Wu, Y., Choi, B. C. F., Guo, X., \& Chang, K. T.-T. (2017). Understanding user adaptation toward a new IT system in organizations: A social network perspective. Journal of the Association of Information Systems, 18(11), 787-813.

Wyatt, S. (2003). Non-users also matter: The construction of users and non-users of the internet. In T. Pinch \& N. Oudshoorn (Eds.), How Users Matter: The Coconstruction of Users and Technology (pp. 67-79). MIT Press.

Zamani, E. D., Giaglis, G. M., \& Pouloudi, A. (2013). A Sensemaking Approach to Tablet Users' Accommodating Practices. International Conference on Information Systems (ICIS 2013), Milan, Italy.

Zamani, E. D., Pouloudi, N., Giaglis, G., \& Wareham, J. (2019). Accommodating practices during episodes of disillusionment with Mobile IT. Information Systems Frontiers. https://doi.org/10.1007/ s10796-019-09972-4.

Publisher's Note Springer Nature remains neutral with regard to jurisdictional claims in published maps and institutional affiliations.
Efpraxia D. Zamani is a Senior Lecturer of Information Systems at The University of Sheffield, UK. Her research is focused on post-adoption user behaviour, enterprise information systems and the organisational and societal implications of IT. Her research work has been published in journals such as the Journal of Information Technology, Government Information Quarterly, Information Systems Frontiers and the International Journal of Electronic Commerce. She is a member of the Editorial Review Boards of the Industrial Management and Data Systems (IMDS), the Journal of Responsible Technology, Futures and Foresight Science and the Journal of Global Information Technology Management.

Nancy Pouloudi is Professor of Information Systems Management and Department Chair (2020-2022) in the Department of Management Science and Technology at the Athens University of Economics and Business, Greece. She holds a PhD in Information Systems from the London School of Economics. Her research focuses on organizational and social issues in information systems adoption and implementation. She is a member of the Editorial Boards of the Journal of the AIS, Information \& Management, Health Policy \& Technology, and the International Journal of Society, Information, Communication \& Ethics. She has served on the editorial boards of the European Journal of Information Systems and IT \& People as well as on the Committees of the European (ECIS) and the Mediterranean (MCIS) Conference on Information Systems. In the period 2010-2013 she was Region 2 (Europe/Middle East/Africa) Representative of the Association for Information Systems (AIS). In 2016 she received the Sandra Slaughter Service Award of the AIS.

George M. Giaglis is Professor of eBusiness at the Athens University of Economics and Business, Greece, and Executive Director of the Institute for the Future of the University of Nicosia, Cyprus. His current research interests are focused on blockchain and digital assets, including decentralized governance and applications. He has published more than 150 articles in leading journals and international conferences, including Decision Support Systems, the Information Systems Journal, the International Journal of Electronic Commerce, and the European Journal of Information Systems.

Jonathan Wareham is Professor/Catedrático of Information Systems of ESADE Business \& Law Schools, Ramon Llull University. He previously served as Dean (Faculty \& Research) and Vice Dean (Research). Dr. Wareham's research has been published, or is forthcoming, in over 80 refereed journals and proceedings such as Organization Science, Decision Sciences, MIS Quarterly, Decision Support Systems, IEEE Transactions on Engineering Management, IEEE Computer, Journal of Medical Internet Research, Journal of the American Society for Information Science and Technology, International Journal of Medical Informatics and numerous others. He serves as Senior Editor of MIS Quarterly, and has held/holds editorial positions with Information Systems Research, Journal of Information Technology, Journal of the Association for Information Systems, Information \& Organization and Journal of Strategic Information Systems. 